\title{
Hybrid-DFT Modeling of Lattice and Surface Vacancies in MnO
}

\author{
Andrew J. Logsdail,*,†॰ Christopher A. Downing, ${ }^{\ddagger, I L}$ Thomas W. Keal, ${ }^{\text {II }}$ Paul Sherwood, ${ }^{\text {II }}$ \\ Alexey A. Sokol, ${ }^{+0}$ and C. Richard A. Catlow \\ ${ }^{\dagger}$ Cardiff Catalysis Institute, School of Chemistry, Cardiff University, Cardiff, CF10 3AT, United Kingdom \\ ${ }^{\ddagger}$ Kathleen Lonsdale Materials Chemistry, Department of Chemistry, University College London, 20 Gordon Street, London, WC1H \\ 0AJ, United Kingdom

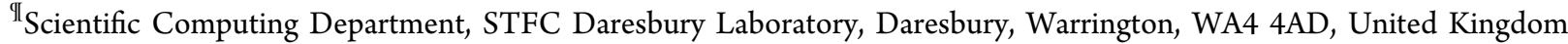 \\ ${ }^{\S}$ UK Catalysis Hub, Research Complex at Harwell, Science and Technology Facilities Council Rutherford Appleton Laboratory, \\ Harwell Science and Innovation Campus, Oxon, OX11 0QX, United Kingdom
}

\section{Supporting Information}

\begin{abstract}
We have investigated the properties of defects in $\mathrm{MnO}$ bulk and at (100) surfaces, as used in catalytic applications, using hybrid-level density functional theory (i.e., inclusion of exact exchange within the exchange-correlation evaluation) in a hybrid QM/MM embedded-cluster approach. Initially, we calculate the formation energy for bulk $\mathrm{Mn}$ and $\mathrm{O}$ vacancies, comparing charged-defect compensation with charge carriers at the Fermi Level $\left(\epsilon_{f}\right)$ and through Schottky defect formation. Oxygen vacancies were also investigated at the (100) surface, where the vacancy formation energy is very similar to the bulk. Defect levels associated with the most stable vacancies are calculated using the $\triangle$ SCF method: all are positioned mid band gap, with surface environments failing to

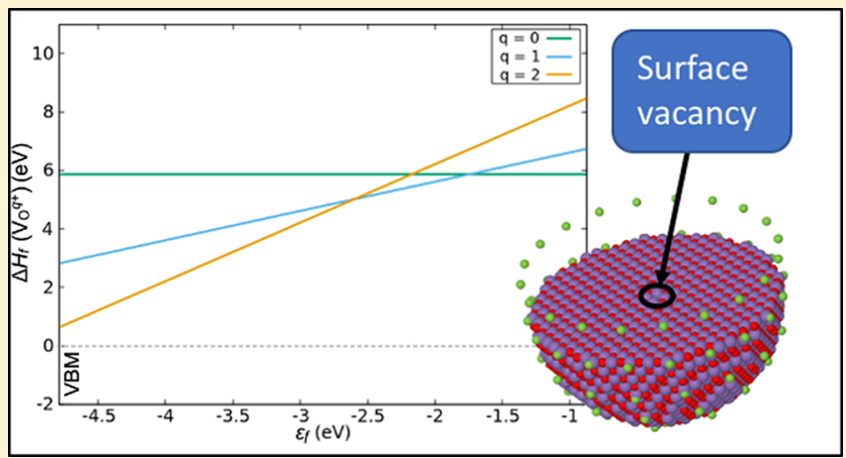
alter strongly the overall nature of the defect relative to bulk. Chemical activity of the (100) MnO surface was considered through the adsorption of a probe $\mathrm{CO}_{2}$ molecule, which is considered the initial step in the transformation of $\mathrm{CO}_{2}$ into hydrocarbons. $\mathrm{CO}_{2}$ adsorption was strongest over a neutral oxygen vacancy, where the associated trapped electrons of the defect transfer to the adsorbate and thus activate it. However, we have shown with our embedded-cluster approach that the neutral oxygen vacancy is not necessarily the dominant species, which has implications when interpreting results for future catalytic applications.
\end{abstract}

\section{INTRODUCTION}

Understanding the properties and stability of material defects is key in order to maximize the impact of materials engineering. Rock salt metal oxides are ideal test systems when studying how defects alter fundamental physico-chemical behavior, ${ }^{1-4}$ with their stability also making them particularly appealing for applications that do not involve ambient conditions, such as heterogeneous catalysis. ${ }^{5-8}$ In particular, rock salt oxides formed from early group 2 alkaline earth metals $(\mathrm{Mg}, \mathrm{Ca})$ have been extensively studied, both with respect to their defect structure and properties ${ }^{9}$ and with the focus on potential applications in the catalytic transformation of $\mathrm{CO}_{2} \cdot{ }^{10,11}$ In these investigations, computational methods lend themselves to investigating both the viability of reaction mechanisms as well as the large compositional search space for novel materials, with systematic investigations establishing a new standard when looking for beneficial material characteristics. $^{12,13}$ Computational screening of this nature was recently used to examine $\mathrm{CO}_{2}$ adsorption on a variety of rock salt (100) surfaces, showing strong surface-adsorbate interactions and charge transfer for a range of materials. ${ }^{14}$ One material that plays an important role in these studies is $\mathrm{MnO}$, which is typically considered as a supporting material or a reaction promoter, rather than an active part of catalytic processes, due to its variable oxidation state; ${ }^{15-19}$ in this highlighted work, however, $\mathrm{MnO}$ was identified as being reactive toward $\mathrm{CO}$ and $\mathrm{CO}_{2}{ }^{18,19}$ This is perhaps unsurprising given that $\mathrm{MnO}$ can be prepared by thermal decomposition of $\mathrm{MnCO}_{3}{ }^{20,21}$ which is done in an anaerobic environment to prevent the formation of higher oxidation state compounds. Observations of chemical reactivity are not without precedent for $\mathrm{MnO}$ : concerted effort has been applied toward characterizing the electronic properties of $\mathrm{MnO}-\mathrm{ZnO}$ mixtures due to hypothesized photocatalytic capabilities. $^{22-27}$ It has also recently been of interest to tune catalytic properties by introducing individual defects, intrinsic or extrinsic, ${ }^{1,6,28-32}$ to the oxide framework; such materials

Special Issue: Hans-Joachim Freund and Joachim Sauer Festschrift

Received: August 12, 2018

Revised: November 1, 2018

Published: November 14, 2018 
have the stability of the host material while displaying novel catalytic chemistry. An example application of this nature is $\mathrm{CO}_{2}$ adsorption over the (100) surface of Mn-doped $\mathrm{MgO}$, with and without neighboring anion vacancies. The results showed that the multivalent $\mathrm{Mn}$ caused chemical bonding between the support and the adsorbate that was not present for undoped-MgO, ${ }^{33}$ which complements experimental observations for mixed $\mathrm{Fe}-\mathrm{MnO} / \mathrm{MgO}$ catalysts as being reactive for the formation of light olefins from syngas. ${ }^{17}$

In this work, we have performed calculations to investigate the defect energetics in the bulk and at the (100) surface of $\mathrm{MnO}$, and also investigated the surface reactivity. Defects, both intrinsic and extrinsic, are key for controlling the chemical properties of catalytic materials and optimizing surface reactivity. However, one of the complexities when investigating magnetic materials like $\mathrm{MnO}$ is the effect of temperature on the spin configuration. At room temperature, $\mathrm{MnO}$ is paramagnetic (PM) and adopts a cubic structure with lattice constant $(a)$ of $4.445 \AA \AA^{34-36}$ but $\mathrm{MnO}$ has a Neél temperature $\left(T_{N}\right)$ of $118 \mathrm{~K},{ }^{37}$ below which it adopts an antiferromagnetic spin-configuration (AFM) with the $\mathrm{d}^{5}$ valence electrons alternating in their spin alignment between nearest neighbor $\mathrm{Mn}^{2+}$ cations. In the case of $\mathrm{MnO}$, the lowest energy AFM arrangement is with the spin aligned in a principal diagonal plane through the crystal $[\mathrm{AFM}(\mathrm{II})]$, rather than in the lowestindex (100), (010) or (001) plane [AFM(I)].37,38 Calculations have confirmed this energetic ordering of spin configurations, with the ferromagnetic (FM) arrangement shown as higher in energy than either AFM option. ${ }^{39-44}$ The AFM(II) spinconfiguration is associated with a rhombohedral distortion to the unit cell: the experimental lattice constant, $a$, is 4.43015$4.4316 \AA$, and the unit cell angle, $\alpha$, is $90.60-90.62^{\circ} .45-47$

In the following sections, we outline our method and results, focusing on the low-energy AFM(II) spin-configuration due to its highest relative stability in athermal conditions as these are the implicit conditions of a static quantum mechanical calculation. We introduce our chosen methodology, hybrid quantum- and molecular-mechanics, and we then investigate the electronic and energetic properties of defects in bulk $\mathrm{MnO}$, providing new insight into the bulk properties of this material. We complement these calculations with an investigation of surface atomic vacancies at the low-energy (100) surface, and finally we test the reactivity of $\mathrm{CO}_{2}$ over both pristine and defective $\mathrm{MnO}$ (100) surfaces.

\section{COMPUTATIONAL METHODOLOGY}

Calculations were performed using the additive hybrid quantum- and molecular-mechanical (QM/MM) embeddedcluster methodology, as realized in the ChemShell software package. ${ }^{48,49} \mathrm{QM}$ and MM energy evaluations were outsourced to the NWChem ${ }^{50}$ and GULP N1-53 $^{50 f t w a r e}$ packages, respectively, and geometry optimizations coordinated by the DL-FIND library. ${ }^{34}$ The accuracy of this method has been previously shown for the study of intrinsic and extrinsic defects in bulk and surface environments of ionic oxides like $\mathrm{MgO},{ }^{55,56}$ $\mathrm{TiO}_{2},{ }^{57-59} \mathrm{In}_{2} \mathrm{O}_{3}, \mathrm{SnO}_{2}$, and $\mathrm{ZnO}{ }^{60}$ The strength of the QM/ $\mathrm{MM}$ embedded-cluster approach is that it allows the affordable use of hybrid-DFT, which is necessary for localizing defects and accurately predicting energetics. The power of this approach toward the accurate modeling of reaction processes is well illustrated previously by the work of Sauer et al. ${ }^{61}$ Additionally, an aperiodic embedded-cluster model allows us to access an unambiguous reference state, namely the vacuum level $(0 \mathrm{~V})$, and also allows the facile study of charged defects, both bulk and surface, with the latter being extremely difficult to perform using periodic models. ${ }^{62,63}$

In this work, the bulk (surface) QM/MM embedded-cluster model is spherical (hemispherical) and has a radius of $30 \AA$. This results in a model that contains $\sim 10000(\sim 5500)$ atoms. Within these (hemi)spherical clusters, the models are partitioned into QM and MM regions, where we define an inner "active" region that encompasses the central QM and $\mathrm{MM}$ atoms, which has a radius of $15 \AA$. This choice of size is based on our previous experiences modeling charged defects in $\mathrm{MgO}$ and noting the relatively local nature of geometric changes. ${ }^{33}$ In total, the "active" regions contain $\sim 1300$ and $\sim 600$ atoms for bulk and surfaces, respectively. In the bulk (surface) models, the central 33 (23) atoms were represented using QM, with all remaining atoms represented using MM interactions. The atoms in the "active" region are able to move during geometry optimization, with an outer "frozen" region to ensure long-range bulk structure. The "frozen" region is $15 \AA$ thick, which is chosen so as to be greater than the force field cutoff and thus ensure there are no energy discontinuities in the $\mathrm{MM}$ energy term. Additionally embedding the entire model is a series of point charges, with their values fitted to reproduce the long-range bulk electrostatic environment for the central "active" region, to an accuracy of $10^{-3} \mathrm{~V}$. During geometry optimization, convergence is deemed complete when the residual forces are lower than $0.015 \mathrm{eV} / \AA$.

For the MM calculations, the energy is calculated using a polarizable-shell interatomic force field (FF), which has Coulomb $\left(E_{\mathrm{MM}}^{\mathrm{Coul}}\right)$, Buckingham $\left(E_{\mathrm{MM}}^{\text {Buck }}\right)$, and spring $\left(E_{\mathrm{MM}}^{\text {spring }}\right)$ terms, defined as: ${ }^{52}$

$$
\begin{aligned}
& E_{\mathrm{MM}}^{\mathrm{Coul}}=k_{e} \frac{q_{i} q_{j}}{r_{i j}} \\
& E_{\mathrm{MM}}^{\text {Buck }}=A \mathrm{e}^{-r_{i j} / \rho}-\frac{C}{r_{i j}{ }^{6}} \\
& E_{\mathrm{MM}}^{\mathrm{spring}}=\frac{1}{2} k_{2} r_{i j}{ }^{2}
\end{aligned}
$$

between two centers with indices $i$ and $j$, separated by a distance $r_{i j}$. The FF parameters are the charge $(q$, in e), the spring constant $\left(k_{2}\right.$, in $\left.\mathrm{eV} \AA^{-2}\right)$, and the Buckingham potential parameters $A(\mathrm{eV}), \rho(\AA)$ and $C\left(\AA^{6} \mathrm{eV}\right)$; and $k_{e}$ is Coloumb's constant. Our work builds on the FF parametrization of Lewis and Catlow (Table 1), ${ }^{64}$ which gives an $\mathrm{MnO}$ lattice parameter (a) of $4.44 \AA$ that matches experiment $(4.45 \AA$ ) for the room temperature, cubic, PM MnO ${ }^{34-36}$ However, this FF does not reproduce the low-temperature AFM(II) rhombohedral unit cell, which is required to prevent unphysical strain occurring from a structural match between the $\mathrm{QM}$ and $\mathrm{MM}$ regions at the $\mathrm{QM} / \mathrm{MM}$ interface. As a remedy, a Lennard-Jones potential $\left(E_{\mathrm{MM}}^{\mathrm{LJ}}\right)$, taking the form of:

$$
E_{\mathrm{MM}}^{\mathrm{LJ}}=-\frac{C_{6}}{r_{i j}{ }^{6}}
$$

was introduced between nearest neighbor $\mathrm{Mn}^{2+}$ cations with opposing spin by using a short-range cutoff of $5 \AA$ to include nearest and next-nearest neighbor $\mathrm{Mn}-\mathrm{Mn}$ interactions. This implementation mimics the attractive exchange interactions between antiparallel spins, with the Buckingham potential continuing to provide short-range repulsion. The $C_{6}$ parameter, 
Table 1. Force Field Parameters for the $\mathrm{MnO}$ Calculations. $^{64} a$

\begin{tabular}{|c|c|c|c|c|}
\hline Coul. and spring & $q_{\text {core }}$ & \multicolumn{2}{|c|}{$q_{\text {shell }}$} & $k_{2}$ \\
\hline $\mathrm{Mn}$ & -1.420 & \multicolumn{2}{|c|}{3.420} & 95.00 \\
\hline $\mathrm{O}$ & 1.000 & \multicolumn{2}{|c|}{-3.000} & 54.76 \\
\hline Buck. & $A$ & $\rho$ & C & $r_{c}$ \\
\hline $\mathrm{Mn}_{\text {shell }}-\mathrm{O}_{\text {shell }}$ & 1007.4 & 0.3262 & 0.0 & 12.0 \\
\hline $\mathrm{O}_{\text {shell }}-\mathrm{O}_{\text {shell }}$ & 22764.3 & 0.1490 & 23.0 & 12.0 \\
\hline \multicolumn{2}{|l|}{ LJ } & \multicolumn{2}{|c|}{$C_{6}$} & $r_{c}$ \\
\hline \multicolumn{2}{|c|}{$\mathrm{Mn}_{\text {core }} \uparrow \uparrow \uparrow \uparrow \uparrow-\mathrm{Mn}_{\text {core }} \downarrow \downarrow \downarrow \downarrow \downarrow \downarrow$} & \multicolumn{2}{|c|}{52.5} & 5.0 \\
\hline
\end{tabular}

${ }^{a}$ Coul., Buck., and LJ are abbreviations/acronyms for Coulomb, Buckingham and Lennard-Jones, respectively. The parameters are the core charge $\left(q_{\text {core }}\right.$ in e), the shell charge $\left(q_{\text {shell }}\right.$, in e), the spring constants $\left(k_{2}\right.$, in $\left.\mathrm{eV} \AA^{-2}\right)$, the Buckingham potential parameters $A$ (in $\mathrm{eV}$ ), $\rho$ (in $\AA$ ), $C$, the Lennard-Jones $C_{6}$ parameter, in units of $\AA^{6} \mathrm{eV}$, and the cutoff for the different potentials $\left(r_{c}\right)$ in $\AA$.

which has units of $\AA^{6} \mathrm{eV}$, was fitted in order to reproduce the low-temperature structure of the AFM(II) MnO phase ( $a=$ $\left.4.43 \AA, \alpha=90.6^{\circ}\right) .^{45-47}$

For the QM calculations, hydrid density functional theory (hybrid-DFT) was used with the B3LYP ${ }^{65-67}$ and B97-3 ${ }^{68}$ exchange-correlation (XC) functionals. Results obtained with B3LYP provide a direct comparison with previous work on $\mathrm{MgO}$, while $\mathrm{B} 97-3$ is a more advanced $\mathrm{XC}$ functional that has been fitted to a more extensive thermochemical data set. A Def2 triple- $\zeta$ valence plus polarization (TZVP) basis set was used for oxygen and carbon, ${ }^{69}$ and a Stuttgart/Dresden relativistic small-core effective core potential (ECP), with modified basis sets, was used for $\mathrm{Mn}:{ }^{70}$ the most diffuse functions were removed to prevent artificial spread of electron density outside the QM region (edited basis set provided in the Supporting Information). ${ }^{33,55}$ At the boundary of the QM region, it is typical to have cation-centered large-core ECPs to contain the electron density; however, no such ECPs have been derived for $\mathrm{Mn}^{2+}$. Given the similar ionic radii of $\mathrm{Mg}^{2+}$ and $\mathrm{Mn}^{2+}$, it was decided that large-core $\mathrm{Mg}^{2+}$ ECPs would be placed at the QM/MM boundary, with such an approach proving successful in a previous investigation of optical transitions for cubic-structured, FM- and AFM-ordered, $\mathrm{MnO}^{23}$

\section{BULK}

3.1. Pristine. A bulk model of $\mathrm{MnO}$ was cut from the FFoptimized AFM(II) crystal structure. The QM/MM cluster was centered on the atomic species of interest: the O-centered model contains $14 \mathrm{Mn}$ and $19 \mathrm{O}$ atoms (Figure 1), whereas the $\mathrm{Mn}$-centered model contains $14 \mathrm{O}$ and $19 \mathrm{Mn}$ atoms. Previous work has shown a model of this size is optimal as it ensures the QM region is large enough not to exhibit quantum confinement effects, which may occur due to the localized nature of the occupied states, while also not being excessively large so as to make calculations prohibitively expensive. ${ }^{33,55,56}$ We also note here that stoichiometry is not a requirement for the $\mathrm{QM}$ region in the $\mathrm{QM} / \mathrm{MM}$ embedded-cluster approach. ${ }^{55-60}$ After geometry optimization, the AFM(II) electronic structure was preserved in both models, with Mulliken analysis showing an average spin density of $4.8 \mathrm{e}$ on each $\mathrm{Mn}^{2+}$ cation when using either XC functional, in agreement with experiment; ${ }^{71}$ however, the geometric structure is noted as being slightly distorted. For both the B3LYP and B97-3 O-centered models of pristine $\mathrm{MnO}$, the

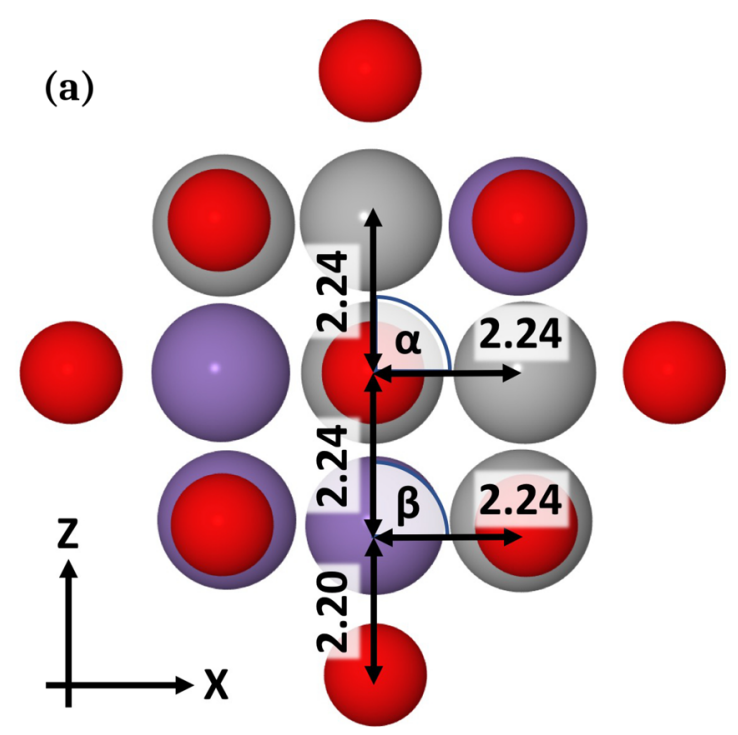

(b)

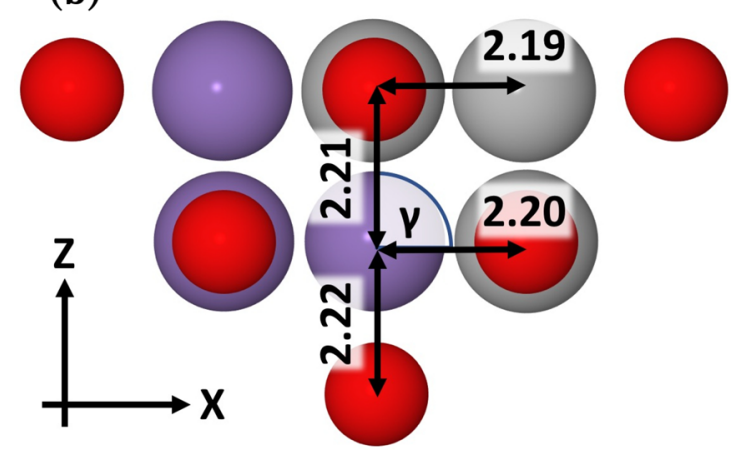

Figure 1. Structures of the QM region in the QM/MM models of the B3LYP-optimized (a) bulk and (b) surface models, as viewed with a cutplane through the $x$ - and $z$-axes. Purple and gray spheres represent $\mathrm{Mn}$ atoms with spin-up and spin-down configurations, respectively, and red spheres represent oxygen atoms. Bond lengths are given in $\AA$, and the denoted angles $\alpha, \beta$, and $\gamma$ are 90.6, 90.6, and 90.4 respectively.

mean bond distances in the QM region stay constant at $2.21 \AA$ but in a range of $2.16-2.24 \AA$, with bond lengths longer in the center of the QM region. Mean bond distances across the QM/MM boundary contracted (expanded) slightly for $\mathrm{O}_{\mathrm{QM}}-$ $\mathrm{Mn}_{\mathrm{MM}}\left(\mathrm{Mn}_{\mathrm{QM}}-\mathrm{O}_{\mathrm{MM}}\right)$ interactions, with averages of 2.18 and $2.24 \pm 0.01 \AA$, respectively. Central bond angles were unaltered $\left(\alpha=90.6^{\circ}\right)$. These results were compared with geometry optimization of a range of QM/MM models with 7, $19,27,33,45,57,63,75$, and 81 atoms in the QM region. It is noted that average bond length within the QM region and across the QM/MM boundary remains relatively constant $( \pm 0.01 \AA)$, with the exception of the $\mathrm{Mn}_{\mathrm{QM}}-\mathrm{O}_{\mathrm{MM}}$ interaction for which $2.24 \AA$ is large compared to the more common observation of 2.21-2.22 $\AA$. Interestingly, the range of bond lengths for those intersecting the QM/MM boundary (and in the MM region) remains stable, whereas within the QM region the range increases up to $2.17-2.27 \AA$ for the 81 -atom QM region, which also results in significant distortion of the bond angles. For the Mn-centered clusters, the distances between central and nearest neighbor atoms also increased, up to 2.25 $\AA$; however, bond lengths in the QM region toward the boundary contracted significantly $(2.15 \AA)$. This contraction 
led to inversion of the bond angle in some cases, with variation between 89.0 and $90.7^{\circ}$. While these observations are indicative of a slight force mismatch between the QM and $\mathrm{MM}$ regions, the structural changes do not adversely affect energetics, as discussed subsequently in our analysis.

The energetic position of the valence band maximum (VBM) can be calculated by simulating the ionization of an electron from the bulk environment in to vacuum, as

$$
\mathrm{MnO}^{0} \rightarrow \mathrm{MnO}^{+}+\mathrm{e}^{-}
$$

The energy of an electron far removed from the bulk (i.e., at the vacuum level) is $0 \mathrm{eV}$, and so the vertical ionization energy $\left(I_{v}\right)$ is

$$
I_{v}=E\left(\mathrm{MnO}^{+}\right)-E\left(\mathrm{MnO}^{0}\right)
$$

As well as $I_{v}$, which represents the instantaneous process of removing an electron, one can subsequently calculate the stabilization of a hole state as the adiabatic ionization $\left(I_{a}\right)$. For both $I_{v}$ and $I_{a}$, the starting structure is that of optimized $\mathrm{MnO}^{0}$ : the nuclear coordinates are frozen for $I_{v}$, allowing only the electronic configuration (and MM shells) to optimize, making this the appropriate method to place the VBM, whereas the nuclear centers are free to move for the $I_{a}$, the energy of which could be compared to emission spectra. We note that for $E\left(\mathrm{MnO}^{+}\right)$, and any other charged $\mathrm{QM} / \mathrm{MM}$ cluster, the $a$ posteriori long-range dielectric correction of Jost is included in the total energy to compensate for the finite size of the polarizable region in our QM/MM model. ${ }^{33,72,73}$

For the O-centered clusters, which we will focus on throughout our work, $I_{v}$ and $I_{a}$ are 4.79 (5.14) eV and 3.46 (3.68) eV, respectively, when using the B3LYP (B97-3) XC functional; for the Mn-centered clusters, $I_{v}$ is 4.76 (5.07) $\mathrm{eV}$ for the same XC functionals. The similarity in $I_{v}$ between our two model configurations gives us significant confidence in the ability to compare the results of our calculations. To further clarify the error bar in our approach, we also calculated $I_{v}$ for the O-centered cluster when varying the size of the QM region between 7, 19, 27, 33, 45, 57, and 63 atoms. The B3LYP calculated values, which were respectively 5.43, 4.63, 4.85, $4.79,4.76,4.75$, and $4.77 \mathrm{eV}$, vary significantly at small sizes, due to quantum confinement effects, but converge to within $0.04 \mathrm{eV}$ for sizes of 33 atoms and greater. This similarity is particularly noteworthy given the structural differences of the respective QM regions, as highlighted above, when changing the QM region size. Overall, we can combine the highlighted differences to present a conservative compound error bar of $\pm 0.1 \mathrm{eV}$ on our results. While previous calculations of $I_{v}$ for bulk $\mathrm{MnO}$ are unavailable, calculated position of the VBM at surfaces have been presented in the range of $4.5-5.5 \mathrm{eV}$ (discussed further in section 4$) ;{ }^{12,13}$ however, we also note that the only available experimental data, taken from photoelectrochemical measurements of PM MnO, shows $I_{v}$ to be considerably greater as $7.09 \mathrm{eV} .^{74}$ This discrepancy between experiment and theory could be related to the differences in magnetic and structural configuration, though neither effect results typically in such significant deviations; therefore, the difference is perhaps more likely due to experimental error and/or DFT methodological choices. Tests show that the ionization potential of gas-phase $\mathrm{Mn}$ atoms match experiment (7.43 eV in experiment, ${ }^{75} 7.64 \mathrm{eV}$ with B3LYP), but ligandfield interactions result in splitting of degenerate levels within the bulk materials: an underestimation of $I_{v}$ with DFT XC functionals has been previously observed for bulk materials and should be remembered when considering the position of both conduction band (CB) and valence band (VB) edges. ${ }^{55}$ Previous literature tells us the VBM is of mixed nature in AFM(II) MnO, with PBE0 giving a 25/75\% split between O $2 \mathrm{p}$ - and $\mathrm{Mn} 3 \mathrm{~d}$-states, respectively; ${ }^{41}$ in our calculations, Mulliken analysis on both the O-centered and Mn-centered models shows that the electron is removed from the $\mathrm{Mn}$ valence shells when forming $\mathrm{MnO}^{+}$, hence the good agreement between the two models, and the remaining hole localizes on an $\mathrm{Mn}$ atom during subsequent geometry relaxation.

The discrete nature of the QM region in the QM/MM cluster, and the resulting quantum confinement, results in a poor representation of the $\mathrm{CB}$ and an overestimation of the band gap, $E_{g}$; therefore, bulk $E_{g}$ has been taken from literature to position the conduction band minimum (CBM). Experimental reports of $E_{g}$ are for the room temperature, PM ordering, and range between 3.6 and $4.9 \mathrm{eV}^{76-78}$ calculated band gaps of 2.9-4.02 eV and 3.5-4.2 eV have been presented for AFM(II) $\mathrm{MnO}$ from hybrid-DFT ${ }^{40-42}$ and $\mathrm{GW}^{12,79,80}$ calculations. In this work, we have taken the result of $E_{g}$ for the B3LYP XC functional $(3.92 \mathrm{eV})$ as this exactly matches one of our XC functionals; ${ }^{40}$ thus, we position the CBM of AFM(II) $\mathrm{MnO}$ using the $I_{v}$ from our O-centered clusters, obtaining $-0.87(-1.22) \mathrm{eV}$ relative to the vacuum level when using the B3LYP (B97-3) XC functionals.

3.2. Intrinsic Defects. In order to illustrate the capabilities of the embedded-cluster QM/MM approach, we have calculated the defect formation energy for neutral and charged vacancies in $\mathrm{MnO}$, as well as the energy levels of trapped electrons/holes at the remaining vacancies. A Kröger-Vink defect notation is used. A neutral cation vacancy may be considered as forming thus

$$
\mathrm{Mn}_{\mathrm{Mn}}^{\mathrm{x}} \rightarrow \mathrm{V}_{\mathrm{Mn}}^{\mathrm{x}}+\mathrm{Mn}_{\mathrm{ref}}^{\mathrm{x}}
$$

with a formation energy of

$$
\Delta H_{f}\left(\mathrm{~V}_{\mathrm{Mn}}^{\mathrm{x}}\right)=E\left(\mathrm{~V}_{\mathrm{Mn}}^{\mathrm{x}}\right)+E\left(\mathrm{Mn}_{\mathrm{ref}}^{\mathrm{x}}\right)-E\left(\mathrm{Mn}_{\mathrm{Mn}}^{\mathrm{x}}\right)
$$

The energy of the reference states, $E\left(\mathrm{Mn}_{\mathrm{ref}}^{\mathrm{x}}\right)$, is defined as $E\left(\mathrm{Mn}_{\mathrm{at}}\right)+\mu(\mathrm{Mn})$, where $E\left(\mathrm{Mn}_{\mathrm{at}}\right)$ is the calculated energy of the gas-phase atom and $\mu(\mathrm{Mn})$ is the chemical potential of $\mathrm{Mn}$. Here, $E\left(\mathrm{Mn}_{\mathrm{at}}\right)$ was calculated as $E\left(\mathrm{Mn}_{\mathrm{at}}{ }^{2+}\right)$ minus the first and second experimental ionization energies, as successfully applied previously for embedded-cluster calculations with modified basis sets. ${ }^{33,81}$ Ideally, $\mu(\mathrm{Mn})$ would also be calculated at the same level of theory as our QM/MM calculations of $\mathrm{MnO}$, which in turn requires calculating $\Delta H_{f}$ $(\mathrm{Mn})$, i.e., the energy of bulk $\mathrm{Mn}$; however, due to the weakness in hybrid-DFTs at representing delocalized states in metallic systems, we found $\Delta H_{f}(\mathrm{Mn})$ to be underestimated by $>1 \mathrm{eV}$ when using hybrid-DFT (see the Supporting Information). This inability to accurately model transition metals is not isolated to our particular choices of hybrid DFT exchange-correlation functionals, but a more general problem for the field as highlighted by Janthon et al. ${ }^{82}$ Thus, in order to minimize the impact of these inaccurate hybrid-DFT models for bulk Mn, the experimental $\Delta H_{f}$ was used for the reference states of $\mathrm{Mn}$ and $\mathrm{MnO}$, and only $\Delta H_{f}\left(\mathrm{O}_{2}\right)$ was calculated to acquire $\mu(\mathrm{Mn})$; from this, the respective products in high- and low-partial pressures of $\mathrm{O}_{2}, p\left(\mathrm{O}_{2}\right)$, are $\mathrm{MnO}(\mathrm{s})\left[\Delta \mathrm{H}_{f}(\mathrm{MnO})\right.$ $\left.-\frac{1}{2} \Delta H_{f}\left(\mathrm{O}_{2}\right)=-126.3 \mathrm{~kJ} \mathrm{~mol}^{-1}\right]$ and $\mathrm{Mn}(\mathrm{s})\left[\Delta H_{f}(\mathrm{Mn})=\right.$ $\left.-279.58 \mathrm{~kJ} \mathrm{~mol}^{-1}\right]^{37,83}$ For the equivalent calculation of $\mathrm{O}_{2}$ vacancies in high- and low- $p\left(\mathrm{O}_{2}\right)$, the reference states are $\mathrm{O}_{2}$ 
(g) $\left[\frac{1}{2} \Delta H_{f}\left(\mathrm{O}_{2}\right)=-258.90 \mathrm{~kJ} \mathrm{~mol}^{-1}\right.$ using B3LYP and $-261.67 \mathrm{~kJ} \mathrm{~mol}^{-1}$ using B97-3] and $\mathrm{MnO}(\mathrm{s})\left[\Delta H_{f}(\mathrm{MnO})\right.$ $\left.\Delta H_{f}(\mathrm{Mn})=-105.62 \mathrm{~kJ} \mathrm{~mol}^{-1}\right],^{37,83}$ respectively.

If a given vacancy forms in a charged state, the energy associated with adding/removing an electron must be included. The Fermi Level $\left(\epsilon_{f}\right)$ is a common source of electrons and holes in traditional semiconductors, depending on its positioning, and its inclusion in our calculations makes $\Delta H_{f}$ :

$$
\Delta H_{f}\left(\mathrm{~V}_{\mathrm{Mn}}^{q}\right)=E\left(\mathrm{~V}_{\mathrm{Mn}}^{q}\right)+E\left(\mathrm{Mn}_{\mathrm{ref}}^{\mathrm{x}}\right)-E\left(\mathrm{Mn}_{\mathrm{Mn}}^{\mathrm{x}}\right)-q \epsilon_{f}
$$

Both positive and negative values of the charge, $q$, are feasible: in the case of $q<0$, electrons are taken from the Fermi Level and thus $-q \epsilon_{f}$ is positive to reflect the energy required for this abstraction; in the case of $q>0$, electrons are transferred to the Fermi level; thus, there is an energy gain. For an oxygen vacancy, the enthalpy of formation is similarly:

$$
\Delta H_{f}=E\left(\mathrm{~V}_{\mathrm{O}}^{q}\right)+E\left(\mathrm{O}_{\mathrm{ref}}^{\mathrm{x}}\right)-E\left(\mathrm{O}_{\mathrm{O}}^{\mathrm{x}}\right)-q \epsilon_{f}
$$

An alternative charge compensation is the formation of Schottky defect pairs, which are prevalent in wide band gap materials, ${ }^{84}$ whereby the charge on a cation vacancy is compensated by an opposing charge on an anion vacancy. For a pair of double-charged vacancies, this is

$$
\begin{aligned}
\mathrm{Mn}_{\mathrm{Mn}}^{\mathrm{x}}+\mathrm{O}_{\mathrm{O}}^{\mathrm{x}} & \rightarrow \mathrm{V}_{\mathrm{Mn}}^{\prime \prime}+\mathrm{Mn}_{\mathrm{at}}^{\bullet \bullet}+\mathrm{V}_{\mathrm{O}}^{\bullet \bullet}+\mathrm{O}_{\mathrm{at}}^{\prime \prime} \\
& \rightarrow \mathrm{V}_{\mathrm{Mn}}^{\prime \prime}+\mathrm{V}_{\mathrm{O}}^{\bullet}+\mathrm{MnO}(\mathrm{s})
\end{aligned}
$$

with the recombination of the charged ions in eq 11 leading to the reformation of $\mathrm{MnO}(\mathrm{s})$ in eq 12 . In this case, $\Delta H_{f}$ for the Schottky defect is

$$
\begin{aligned}
\Delta H_{f}\left(\mathrm{~V}_{\mathrm{Mn}}^{\prime \prime}+\mathrm{V}_{\mathrm{O}}^{\bullet \bullet}\right)= & E\left(\mathrm{~V}_{\mathrm{Mn}}^{\prime \prime}\right)+E\left(\mathrm{~V}_{\mathrm{O}}^{\bullet \bullet}\right)+E[\mathrm{MnO}(\mathrm{s})] \\
& -E\left(\mathrm{Mn}_{\mathrm{Mn}}^{\mathrm{x}}\right)-E\left(\mathrm{O}_{\mathrm{O}}^{\mathrm{x}}\right)
\end{aligned}
$$

where we calculate $E[\mathrm{MnO}(\mathrm{s})]$ as

$$
\begin{aligned}
E[\mathrm{MnO}(\mathrm{s})]=E\left(\mathrm{Mn}_{a t}^{\mathrm{x}}\right) & +\Delta H_{f}(\mathrm{Mn})+E\left(\mathrm{O}_{a t}^{\mathrm{x}}\right) \\
& +\frac{1}{2} \Delta H_{f}\left(\mathrm{O}_{2}\right)+\Delta H_{f}[\mathrm{MnO}(\mathrm{s})]
\end{aligned}
$$

B3LYP-calculated defect formation energies are presented in Figure 2 for the atomic vacancies. For $\mathrm{O}$ vacancies, calculated with the O-centered model, $\mathrm{V}_{\mathrm{O}}^{\bullet \bullet}$ is the most stable at low $\epsilon_{f}$ with the neutral $V_{\mathrm{O}}^{\mathrm{x}}$ defect preferred as $\epsilon_{f}$ tends toward $\epsilon_{\mathrm{CBM}}$; however, the $\mathrm{V}_{\mathrm{O}}$ defects are only more favorable than $\mathrm{V}_{\mathrm{Mn}}$ under high- $p\left(\mathrm{O}_{2}\right)$ when $\epsilon_{f}$ is in the lower half of the band gap. The neutral and negatively charged $V_{O}$ defects show little disruption of the perfect bulk structure, with minimal atomic displacements. Mulliken analysis shows the two electrons $\left(\mathrm{e}^{\prime}\right)$ freed when forming the $\mathrm{V}_{\mathrm{O}}^{\mathrm{x}}$ defect would be trapped in the vacancy, forming an F-center, with an $\mathrm{F}^{+}$-center also stable when one of the defect electrons has been removed i.e. a $V_{O}^{\bullet}$ defect. Unsurprisingly, negatively charged $\mathrm{V}_{\mathrm{O}}$ sites $\left(\mathrm{V}_{\mathrm{O}}^{\prime}\right.$ and $\left.\mathrm{V}_{\mathrm{O}}^{\prime \prime}\right)$ are unstable at all values of $\epsilon_{f}$.

For $\mathrm{Mn}$ vacancies, calculated with the Mn-centered model, $\Delta H_{f}$ decreases with $q$ when $\epsilon_{f}=\epsilon_{C B M}$, and increases with $q$ when $\epsilon_{f}=\epsilon_{V B M}$ : this shows that the defects would donate electrons when $\epsilon_{f}$ is low (large energy gain) and accept electrons when $\epsilon_{f}$ is high (small energy cost). For the B3LYP $\mathrm{XC}$ functional, we calculate that $\Delta H_{f}\left(\mathrm{~V}_{\mathrm{Mn}}^{\prime \prime}\right)$ is exothermic
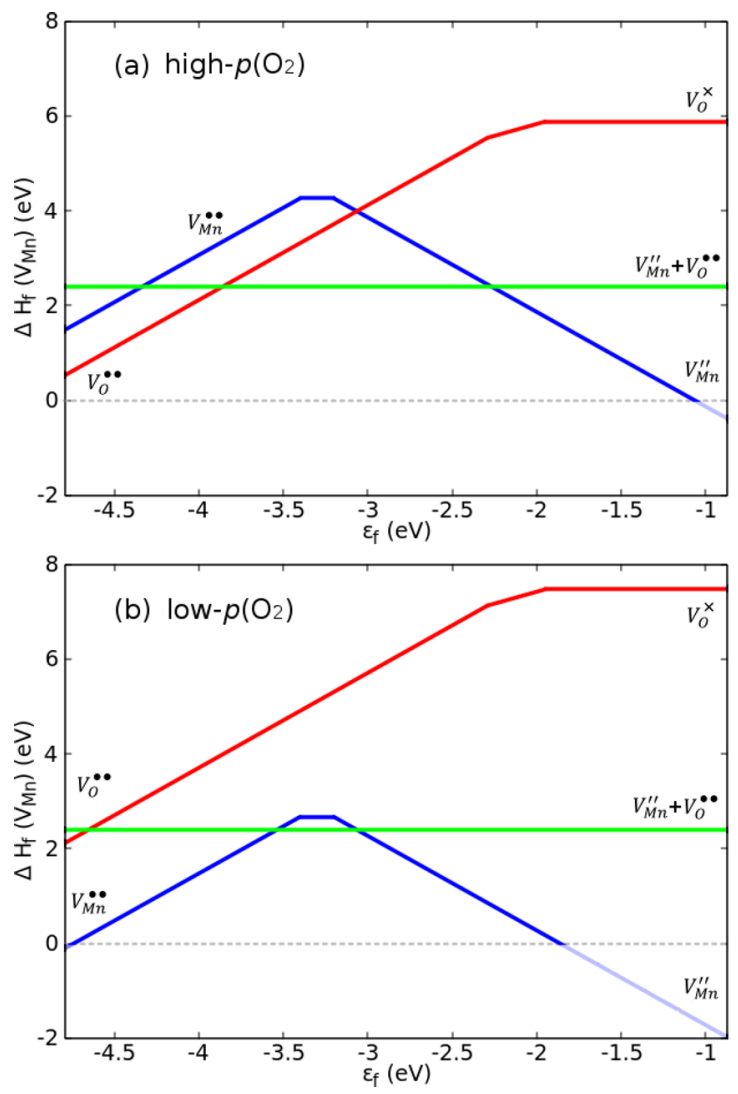

Figure 2. $\Delta H_{f}$ as a function of $\epsilon_{f}$ for $\mathrm{V}_{\mathrm{Mn}}, \mathrm{V}_{\mathrm{O}}$, and Schottky defects, given in blue, red and green, respectively, calculated using the B3LYP $\mathrm{XC}$ functional for (a) high- and (b) low- $p\left(\mathrm{O}_{2}\right)$ conditions. Only the lowest energy defect, of any given type, is marked at any given value of $\epsilon_{f}$ full graphs of all values of $\Delta H_{f}$ for all values of $q$, are provided in the Supporting Information. The minimum and maximum of $\epsilon_{f}$ on the $x$-axis represents the band edges for the valence and conduction band, respectively. The $0 \mathrm{eV}$ line on the $y$-axis, splitting endo- and exothermic processes, is marked by a gray dashed line; $\Delta H_{f}$ values below $0 \mathrm{eV}$ are physically infeasible and thus given in a pale color.

when $\epsilon_{f}=\epsilon_{C B M}$ at both low- and high- $p\left(\mathrm{O}_{2}\right)$; we note that ntype conditions of $\epsilon_{f}$ would require an excess of electrons generated from e.g. oxygen vacancies. In previous literature, ntype conditions have more commonly been considered: Aschauer et al. presented results from periodic PBESol+U calculations with $\epsilon_{f}$ positioned $2.8 \mathrm{eV}$ above the VBM, i.e. toward the CBM, and found that $\Delta H_{f}\left(\mathrm{~V}_{\mathrm{Mn}}^{\prime \prime}\right)$ was $1.5 \mathrm{eV}$ lower than $\Delta H_{f}\left(\mathrm{~V}_{\mathrm{Mn}}^{\prime}\right)$, which in turn was $1.7 \mathrm{eV}$ more preferable than $\Delta H_{f}\left(\mathrm{~V}_{\mathrm{Mn}}^{\mathrm{x}}\right)$; they also reported $\Delta H_{f}\left(\mathrm{~V}_{\mathrm{O}}^{\bullet \bullet}\right)$ as $4.5 \mathrm{eV}$ higher in energy than $\Delta H_{f}\left(\mathrm{~V}_{\mathrm{Mn}}^{\prime \prime}\right){ }^{85}$ These observations are in agreement with our results, with the same $\epsilon_{f}$ positioning giving respective differences between $\Delta H_{f}\left(\mathrm{~V}_{\mathrm{Mn}}^{\prime \prime}\right), \Delta H_{f}\left(\mathrm{~V}_{\mathrm{Mn}}^{\prime}\right)$ and $\Delta H_{f}\left(\mathrm{~V}_{\mathrm{Mn}}^{\mathrm{x}}\right)$ of 1.27 and $1.13 \mathrm{eV}$ (Figure S1, Supporting Information), and between $\Delta H_{f}\left(\mathrm{~V}_{\mathrm{Mn}}^{\prime \prime}\right)$ and $\Delta H_{f}\left(\mathrm{~V}_{\mathrm{O}}^{\bullet \bullet}\right)$ of 4.26 (7.45) eV for high (low)- $p\left(\mathrm{O}_{2}\right)$. Previous experimental work focuses on the dominant $\mathrm{Mn}$ vacancy at varying high temperatures $(T>1000 \mathrm{~K})$, the modeling of which is beyond the scope of this work, but generally notes the prevalence of $\mathrm{V}_{\mathrm{Mn}}^{\prime}{ }^{86}$

As the VBM is lower at $-5.14 \mathrm{eV}$ for $\mathrm{B} 97-3$, we observe that both $\Delta H_{f}\left(\mathrm{~V}_{\mathrm{Mn}}^{\prime \prime}\right)$ and $\Delta H_{f}\left(\mathrm{~V}_{\mathrm{Mn}}^{\bullet \bullet}\right)$ are exothermic for $\epsilon_{f}=\epsilon_{\mathrm{CBM}}$ and $\epsilon_{V B M}$, respectively, under low- $p\left(\mathrm{O}_{2}\right)$ conditions. At both high and low values of $\epsilon_{f}$, the transition from endothermic to exothermic for $\Delta H_{f}$ indicates the limit for $\epsilon_{f}$ in this material as, 
in the exothermic regime, the material properties would change due to the propensity for defect formation. Thermodynamic stability regimes for the singly charged $V_{M n}^{\prime}$ and $V_{M n}^{\bullet}$ defects are not observed for either B3LYP or B97-3.

Structurally, $\mathrm{V}_{\mathrm{Mn}}^{\prime \prime}$ formation results in expansion around the vacant site, with contraction of $\mathrm{Mn}-\mathrm{O}$ bonds between neighboring atoms to compensate for the lost coordination. For the B3LYP optimized model, $\mathrm{Mn}-\mathrm{O}$ bonds around the $\mathrm{V}_{\mathrm{Mn}}^{\prime \prime}$ defect are 2.12-2.14 $\AA$, in agreement with Aschauer et al., who report bond lengths of $2.11 \AA{ }^{85}$ while we observe shorter bonds of $\sim 2.01 \AA$ for bonds between $\mathrm{O}$ atoms neighboring the defect and $\mathrm{Mn}$ atoms at the edge of the QM region. As the charge of QM region is reduced (i.e., electrons are removed), much shorter $\mathrm{Mn}-\mathrm{O}$ bonds are observed: for $\mathrm{V}_{\mathrm{Mn}}^{\prime}$ there is a shorter bond of $1.98 \AA$; for $\mathrm{V}_{\mathrm{Mn}}^{\mathrm{x}}$, two bonds of 1.81 and $1.88 \AA$ are observed; for $\mathrm{V}_{\mathrm{Mn}}^{\circ}$ there is an additional bond of $1.98 \AA$; and for $\mathrm{V}_{\mathrm{Mn}}^{\bullet \bullet}$, four bonds of between 1.81 and $1.88 \AA$ are calculated. These shorter bonds are all indicative of $\mathrm{Mn}-\mathrm{O}$ bond lengths after the oxidation of $\mathrm{Mn}^{2+}$ to $\mathrm{Mn}^{3+42,85,87}$ with Aschauer et al. reporting distances of $1.92 \AA$ for the PBESol+U approach. For B97-3, similar structural observations are made, except that for $\mathrm{V}_{\mathrm{Mn}}^{\prime}$ and $\mathrm{V}_{\mathrm{Mn}}^{\bullet}$ the short bonds are all below 1.86 $\AA$; however, this geometric difference does not appear to influence the defect energetics as neither of the singly charged defects are stable with either XC functional. Mulliken spin analysis shows that the holes $\left(\mathrm{h}^{\bullet}\right)$ created by removing a lattice $\mathrm{Mn}$ cation localize on nearest neighbor Mn sites, forming $\mathrm{Mn}^{3+}$ cations $\left(\mathrm{Mn}_{\mathrm{Mn}}^{\bullet}\right)$, which is consistent for $\mathrm{V}_{\mathrm{Mn}}^{\prime}$ through to $\mathrm{V}_{\mathrm{Mn}}^{\bullet}$. Additionally, via a comparison of states of different multiplicity and Mulliken spin analysis, we observe that the singly charged defects of $\mathrm{V}_{\mathrm{Mn}}^{\prime}$ and $\mathrm{V}_{\mathrm{Mn}}^{\circ}$ are $>1.5 \mathrm{eV}$ more stable when the defect electron aligns with the $\mathrm{d}^{5}$ valence electrons of the removed $\mathrm{Mn}$ atom, i.e. in agreement with the AFM(II) configuration.

In general, $\mathrm{MnO}$ is characterized by experiment as a p-type material (i.e., rich in $h^{\bullet}$ charge carriers) due to $\mathrm{Mn}$ vacancies caused by an excess of oxygen, with investigations having been performed exclusively at room temperature or higher; thus considering cubic, paramagnetic $\mathrm{MnO} .^{35,88,89}$ O'Keeffe et al. stated that the majority defects in their samples were $\mathrm{V}_{\mathrm{Mn}}^{\prime \prime}$, with charge compensation via two $\mathrm{Mn}_{\mathrm{Mn}}^{\bullet}$ centers and ${ }^{1} /{ }_{2} \mathrm{O}_{2}(\mathrm{~g}) ;{ }^{35}$ in our calculations, Mulliken analysis shows that multiple $\mathrm{Mn}_{\mathrm{Mn}}^{\bullet}$ defects are the preferred stabilizer for all $\mathrm{V}_{\mathrm{Mn}}$ defects, but the formation enthalpies imply that $\mathrm{V}_{\mathrm{Mn}}^{\prime \prime}$ would only form with $\epsilon_{f}$ positioned midgap or higher (Figure 2). Our results for low$p\left(\mathrm{O}_{2}\right)$ agree with expectation of $\mathrm{V}_{\mathrm{Mn}}$ being most stable; for high- $p\left(\mathrm{O}_{2}\right)$, our calculations show competition between the $\mathrm{V}_{\mathrm{O}}^{\bullet \bullet}$ and $\mathrm{V}_{\mathrm{Mn}}^{\bullet \bullet}$ defects at low $\epsilon_{f}$, which would be shifted to further favor $\mathrm{V}_{\mathrm{O}}^{\bullet \bullet}$ if we were to consider an $\mathrm{MnO}_{2}$ (s) reference state, which is most likely at high- $p\left(\mathrm{O}_{2}\right): \mu(\mathrm{Mn})=-2.2 \mathrm{~kJ}$ $\mathrm{mol}^{-1}$ i.e. the $\Delta H_{f}\left(\mathrm{~V}_{\mathrm{Mn}}\right)$ line would be shifted further upward. ${ }^{37,83}$ A possible source of this difference is the temperature and phase of the $\mathrm{MnO}$ in our work, although we also suggest that a lack of long-distance exchange coupling may have affected the $\mathrm{V}_{\mathrm{Mn}}$ calculations, which could possibly be rectified by consideration of a larger QM region. Overall, the presence of a stability window for $\mathrm{e}^{\prime}$ charge carriers is in agreement with (high temperature) Hall measurements that show the existence of $\mathrm{e}^{\prime}$ charge carriers with higher mobility than $\mathrm{h}^{\bullet}$ at low- $\mathrm{p}\left(\mathrm{O}_{2}\right)^{88,90-92}$

We present $\Delta H_{f}$ for vacancy defects in Table 2, compared with $\epsilon_{f}$-compensated defects in their most favored conditions, i.e. elemental products, when $\epsilon_{f}$ is equal to the midgap branch
Table 2. Formation Enthalpy (eV) When Using the B3LYP (B97-3) XC Exchange-Correlation Functional for Various Defects, both Atomic Vacancies and Combined SchottkyType, in a Variety of Charge States When the Fermi Level Is Positioned Mid Band Gap, i.e., Equidistant from Valence and Conduction Band Edges ${ }^{a}$

\begin{tabular}{|c|c|}
\hline defect reactions & $\Delta H_{f}(\mathrm{eV})$ \\
\hline \multicolumn{2}{|c|}{ oxygen vacancy, low- $p\left(\mathrm{O}_{2}\right)$} \\
\hline $\mathrm{O}_{\mathrm{O}}^{\mathrm{x}} \rightarrow \mathrm{V}_{\mathrm{O}}^{\prime \prime}+2 \mathrm{~h}^{\bullet \bullet}+\mathrm{MnO}(\mathrm{s})$ & $12.84(13.63)$ \\
\hline $\mathrm{O}_{\mathrm{O}}^{\mathrm{x}} \rightarrow \mathrm{V}_{\mathrm{O}}^{\prime}+\mathrm{h}^{\bullet}+\mathrm{MnO}(\mathrm{s})$ & $10.07(10.29)$ \\
\hline $\mathrm{O}_{\mathrm{O}}^{\mathrm{x}} \rightarrow \mathrm{V}_{\mathrm{O}}^{\mathrm{x}}+\mathrm{MnO}(\mathrm{s})$ & $7.47(7.17)$ \\
\hline $\mathrm{O}_{\mathrm{O}}^{\mathrm{x}} \rightarrow \mathrm{V}_{\mathrm{O}}^{\bullet}+\mathrm{e}^{\prime}+\mathrm{MnO}(\mathrm{s})$ & $6.58(6.13)$ \\
\hline $\mathrm{O}_{\mathrm{O}}^{\mathrm{x}} \rightarrow \mathrm{V}_{\mathrm{O}}^{\bullet \bullet}+2 \mathrm{e}^{\prime}+\mathrm{MnO}(\mathrm{s})$ & $6.03(5.40)$ \\
\hline \multicolumn{2}{|c|}{ oxygen vacancy, high- $p\left(\mathrm{O}_{2}\right)$} \\
\hline $\mathrm{O}_{\mathrm{O}}^{\mathrm{x}} \rightarrow \mathrm{V}_{\mathrm{O}}^{\prime \prime}+2 \mathrm{~h} \cdot \boldsymbol{*}+{ }^{1} / 2 \mathrm{O}_{2}(\mathrm{~g})$ & $11.25(12.04)$ \\
\hline $\mathrm{O}_{\mathrm{O}}^{\mathrm{x}} \rightarrow \mathrm{V}_{\mathrm{O}}^{\prime}+\mathrm{h}^{\bullet}+{ }^{1} /{ }_{2} \mathrm{O}_{2}(\mathrm{~g})$ & $8.48(8.70)$ \\
\hline $\mathrm{O}_{\mathrm{O}}^{\mathrm{x}} \rightarrow \mathrm{V}_{\mathrm{O}}^{\mathrm{x}}+{ }^{1} /{ }_{2} \mathrm{O}_{2}(\mathrm{~g})$ & $5.88(5.58)$ \\
\hline $\mathrm{O}_{\mathrm{O}}^{\mathrm{x}} \rightarrow \mathrm{V}_{\mathrm{O}}^{\mathbf{0}}+\mathrm{e}^{\prime}+1 / 2 \mathrm{O}_{2}(\mathrm{~g})$ & $4.99(4.54)$ \\
\hline $\mathrm{O}_{\mathrm{O}}^{\mathrm{x}} \rightarrow \mathrm{V}_{\mathrm{O}}^{\bullet \bullet}+2 \mathrm{e}^{\prime}+1 / 2 \mathrm{O}_{2}(\mathrm{~g})$ & $4.44(3.81)$ \\
\hline \multicolumn{2}{|c|}{ manganese vacancy, low- $p\left(\mathrm{O}_{2}\right)$} \\
\hline $\mathrm{Mn}_{\mathrm{Mn}}^{\mathrm{x}} \rightarrow \mathrm{V}_{\mathrm{Mn}}^{\prime \prime}+2 \mathrm{~h}^{\bullet}+\mathrm{Mn}(\mathrm{s})$ & $1.95(2.76)$ \\
\hline $\mathrm{Mn}_{\mathrm{Mn}}^{\mathrm{x}} \rightarrow \mathrm{V}_{\mathrm{Mn}}^{\prime}+\mathrm{h}^{\bullet}+\mathrm{Mn}(\mathrm{s})$ & $2.38(2.92)$ \\
\hline $\mathrm{Mn}_{\mathrm{Mn}}^{\mathrm{x}} \rightarrow \mathrm{V}_{\mathrm{Mn}}^{\mathrm{x}}+\mathrm{Mn}(\mathrm{s})$ & $2.67(2.74)$ \\
\hline $\mathrm{Mn}_{\mathrm{Mn}}^{\mathrm{x}} \rightarrow \mathrm{V}_{\mathrm{Mn}}^{\circ}+\mathrm{e}^{\prime}+\mathrm{Mn}(\mathrm{s})$ & $3.35(3.10)$ \\
\hline $\mathrm{Mn}_{\mathrm{Mn}}^{\mathrm{x}} \rightarrow \mathrm{V}_{\mathrm{Mn}}^{\bullet \bullet}+2 \mathrm{e}^{\prime}+\mathrm{Mn}(\mathrm{s})$ & $3.81(3.11)$ \\
\hline \multicolumn{2}{|c|}{ manganese vacancy, high-p $\left(\mathrm{O}_{2}\right)$} \\
\hline $\mathrm{Mn}_{\mathrm{Mn}}^{\mathrm{x}} \rightarrow \mathrm{V}_{\mathrm{Mn}}^{\prime \prime}+2 \mathrm{~h}^{\bullet}+\mathrm{MnO}(\mathrm{s})$ & $3.54(4.35)$ \\
\hline $\mathrm{Mn}_{\mathrm{Mn}}^{\mathrm{x}} \rightarrow \mathrm{V}_{\mathrm{Mn}}^{\prime}+\mathrm{h}^{\bullet}+\mathrm{MnO}(\mathrm{s})$ & $3.97(4.51)$ \\
\hline $\mathrm{Mn}_{\mathrm{Mn}}^{\mathrm{x}} \rightarrow \mathrm{V}_{\mathrm{Mn}}^{\mathrm{x}}+\mathrm{MnO}(\mathrm{s})$ & $4.26(4.33)$ \\
\hline $\mathrm{Mn}_{\mathrm{Mn}}^{\mathrm{x}} \rightarrow \mathrm{V}_{\mathrm{Mn}}^{*}+\mathrm{e}^{\prime}+\mathrm{MnO}(\mathrm{s})$ & $4.94(4.69)$ \\
\hline $\mathrm{Mn}_{\mathrm{Mn}}^{\mathrm{x}} \rightarrow \mathrm{V}_{\mathrm{Mn}}^{\bullet \bullet}+2 \mathrm{e}^{\prime}+\mathrm{MnO}(\mathrm{s})$ & $5.40(4.69)$ \\
\hline \multicolumn{2}{|l|}{ Schottky pair } \\
\hline $\mathrm{Mn}_{\mathrm{Mn}}^{\mathrm{x}}+\mathrm{O}_{\mathrm{O}}^{\mathrm{x}} \rightarrow \mathrm{V}_{\mathrm{Mn}}^{\prime \prime}+\mathrm{V}_{\mathrm{O}}^{\bullet \bullet}+\mathrm{MnO}(\mathrm{s})$ & $2.40(2.57)$ \\
\hline $\mathrm{Mn}_{\mathrm{Mn}}^{\mathrm{x}}+\mathrm{O}_{\mathrm{O}}^{\mathrm{x}} \rightarrow \mathrm{V}_{\mathrm{Mn}}^{\prime}+\mathrm{V}_{\mathrm{O}}^{\cdot}+\mathrm{MnO}(\mathrm{s})$ & $3.38(3.47)$ \\
\hline $\mathrm{Mn}_{\mathrm{Mn}}^{\mathrm{x}}+\mathrm{O}_{\mathrm{O}}^{\mathrm{x}} \rightarrow \mathrm{V}_{\mathrm{Mn}}^{\mathrm{x}}+\mathrm{V}_{\mathrm{O}}^{\mathrm{x}}+\mathrm{MnO}(\mathrm{s})$ & $4.56(4.33)$ \\
\hline $\mathrm{Mn}_{\mathrm{Mn}}^{\mathrm{x}}+\mathrm{O}_{\mathrm{O}}^{\mathrm{x}} \rightarrow \mathrm{V}_{\mathrm{Mn}}^{\cdot}+\mathrm{V}_{\mathrm{O}}^{\prime}+\mathrm{MnO}(\mathrm{s})$ & $7.84(7.81)$ \\
\hline $\mathrm{Mn}_{\mathrm{Mn}}^{\mathrm{x}}+\mathrm{O}_{\mathrm{O}}^{\mathrm{x}} \rightarrow \mathrm{V}_{\mathrm{Mn}}^{\cdot \bullet}+\mathrm{V}_{\mathrm{O}}^{\prime \prime}+\mathrm{MnO}(\mathrm{s})$ & $11.07(11.15)$ \\
\hline
\end{tabular}

point. As shown in eq 13, Schottky defects are mutually cooperative as holes and electrons recombine. Our results show that a Schottky defect with $\mathrm{Mn}^{2+} / \mathrm{O}^{2-}$ pairings are energetically most favorable. By summing $\Delta H_{f}$ for the chargecarrier-compensated vacancies and comparing to the formation energy of Schottky defects, we also see that, when $\epsilon_{f}$ is positioned midgap or higher (i.e., n-type), this Schottky defect is more favorable than all possible combinations of chargecarrier-compensated defects; however, in general the individual $\epsilon_{f}$-compensated defects remain energetically more preferable. Experimentally, Schottky defects were considered previously by Crevecoeur and de Wit in order to explain conductivity measurements; ${ }^{91}$ however, further work by Pai and Honig concluded that a two-carrier model in $\mathrm{MnO}$ is very unlikely. ${ }^{92}$ As an additional note, we see in Table 2 that the most stable $\mathrm{V}_{\mathrm{Mn}}$ defects differ between the B3LYP and B97-3 XC functionals at the midgap point. This difference occurs because of the larger $I_{v}$ when using B97-3 $(5.14 \mathrm{eV})$ compared to B3LYP $(4.79 \mathrm{eV})$, which in turn lowers the energy of the midgap point and favors the loss of $\mathrm{e}^{\prime}$ charge carriers more when using B97-3 than with B3LYP.

The energy levels of electrons trapped at defect sites are presented in Figure 3 . Here, the $\Delta S C F$ method (analogous to 


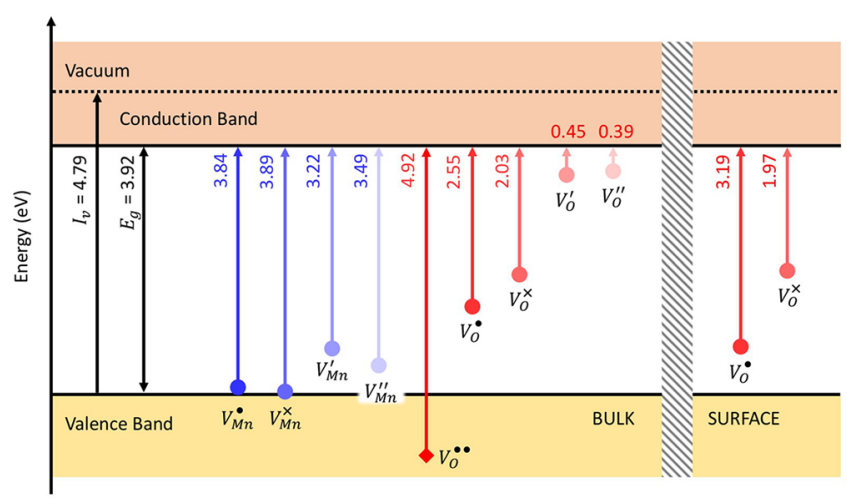

Figure 3. Pictorial representation of defect levels for neutral and charged lattice vacancies in the bulk (left) and at the surface (right) of $\mathrm{MnO}$, as calculated using the B3LYP XC functional. All energies are in $\mathrm{eV}$, with the valence (VB) and conduction band (CB) marked in gold and pink, respectively, and the vacuum level also marked with a dashed horizontal line, as defined by combining the ionization potential $\left(I_{v}\right)$ and the energetic band gap $\left(E_{g}\right)$. Mn and $\mathrm{O}$ vacancy levels are labeled and their distance from the $C B$ is represented by blue and red arrows, respectively, with the color scheme matched to the equivalent charged systems in Figure 2; defect levels marked with circles are trap states in the band gap, while those marked with diamonds are resonant in the VB.

eq 6) was used to calculate the energy levels; ${ }^{93}$ when coupled with values of $I_{v}$ and $E_{g}$, one can determine the position of defects relative to the VBM and CBM. Starting with the Mn vacancies, the sites with two and one associated electrons $\left(\mathrm{V}_{\mathrm{Mn}}^{\prime \prime}\right.$ and $\mathrm{V}_{\mathrm{Mn}}^{\prime}$, respectively) are mid band gap, as may be expected from the behavior of cation defects in similar materials e.g. $\mathrm{V}_{\mathrm{Mg}}$ in $\mathrm{MgO}^{94}$ and $\mathrm{V}_{\mathrm{Zn}}$ in $\mathrm{ZnO} .^{95}$ However, unlike $\mathrm{V}_{\mathrm{Zn}}$, neutral and positive $\mathrm{V}_{\mathrm{Mn}}$ defects are positioned at the VBM. In the case of both $V_{M n}^{\prime}$ and $V_{M n}^{*}$ it is noted that the electron energy levels are higher than defects with an extra electron, further consolidating our observation that these defects are unstable; similar results are observed for the B97-3, as shown in the Supporting Information, in agreement with our observations from Table 2. Such results are not observed for $V_{O}$, where $V_{O}^{x}$ and $\mathrm{V}_{\mathrm{O}}^{\bullet}$ are positioned midgap, similar to the negatively charged $\mathrm{Mn}$ vacancies and the equivalent sites that have been well studied in $\mathrm{MgO} .^{55,94}$ Negatively charged $\mathrm{V}_{\mathrm{O}}$ sites are positioned very close to the CBM and are not expected to be stable.

\section{4. (100) SURFACE}

4.1. Pristine. The (100) surface is the most stable for $\mathrm{MnO}$, as with many other rock salt oxides, ${ }^{96}$ and it is considered here for reactivity investigations. A surface model was prepared at the MM level, using the AFM(II) configuration, with minor rumpling effects occurring such that the $\mathrm{O}$ atoms displaced $0.01 \AA$ outward $(0.5 \%$ change in bond lengths), relative to the $\mathrm{Mn}$ atoms, and the distance between the top-surface layer and subsurface layer contracted to $2.20 \AA$ ( $0.5 \%$ change in interlayer distance). The results for rumpling are mixed in the previous literature, with MEIS ${ }^{97}$ and LEED $^{98}$ giving inward and outward $O$ displacement, respectively; likewise, computational results for the LDA XC functional give retraction of $\mathrm{O}$ from the surface, ${ }^{99}$ while $\mathrm{PBE}$ and $\mathrm{PBE}+\mathrm{U}$ give outward $\mathrm{O}$ displacement by $1.3-1.6 \% .{ }^{100}$ The results for interlayer contraction are more consistent within each method, yet contradictory between theory and experiment: MEIS and LEED indicate that the distance between surface and subsurface layers increases, by $0.1-$ $1.1 \%,{ }^{97,98}$ whereas DFT gives interlayer contraction by $0.3-$ $1.6 \%{ }^{99,100}$ Our calculated displacements match previous computations well, and we note that the error bars on experiment are large compared to the values being considered.

A QM/MM model was constructed from our MM surface, centered on a surface oxygen atom; structural optimization resulted in atom displacements of only $0.01 \AA(0.5 \%)$ compared to the MM model. The surface ionization potential was then calculated using eq 6, with both high- and low-spin configurations considered for the $\mathrm{MnO}^{+}$surface: a high-spin configuration corresponds to ionization from the $\mathrm{O} 2 \mathrm{p}$-orbitals, whereas the low-spin configuration corresponds to removing an electron from the Mn 3d-orbitals. Our calculations show that the highest occupied states (VBM) belong to the Mn 3dorbitals, for which $I_{v}$ is $4.77(5.09) \mathrm{eV}$ and $I_{a}$ is $3.32(3.52) \mathrm{eV}$ when using the B3LYP (B97-3) XC functional, whereas the O 2 p-states are marginally lower in energy with $I_{v}=4.95$ (5.29) $\mathrm{eV}$, for the same XC functionals. We note that our results for $I_{v}$ and $I_{a}$ are similar to bulk: for the favorable low spin ionization of the surface, $I_{v}$ differs by $<0.1 \mathrm{eV}$ and $I_{a}$ by $<0.2 \mathrm{eV}$. Mulliken analysis shows that this similarity is because surface ionization removes an electron from a subsurface, rather than surface, $\mathrm{Mn}$ cation. Further calculations using constrained DFT, whereby the ionized electron is removed specifically from a surface atom, result in $I_{v}=5.06$ and $5.43 \mathrm{eV}$ for B3LYP and B97-3 XC functionals, respectively, which indicates the surface valenceband bending downward.

Motivated by these results, we also calculated second and third ionization energies for the $\mathrm{MnO}$ surface. It was noted that the lowest energy configurations for the vertical ionization of a second electron is with two $\mathrm{Mn}^{3+}$ cations positioned subsurface, forming a $\left[\mathrm{Mn}^{3+}\right]_{2}$ complex, which is more stable than a $\mathrm{Mn}^{4+}$ positioned subsurface or on the surface; the respective energetic ordering is $5.65(5.97)<6.27(6.72)<$ $6.45(6.91) \mathrm{eV}$ when using the B3LYP (B97-3) XC functional. The $\left[\mathrm{Mn}^{3+}\right]_{2}$ configuration was also more favorable for $I_{a}$. Analogous to eq 9, we then looked at formation energies of the ionized surface defects, finding that $\mathrm{Mn}^{3+}$ through to $\mathrm{Mn}^{5+}$, and combinations therein, would be exothermic as $\epsilon_{f}$ approaches the VBM; isolated occurences of $\mathrm{Mn}^{3+}$ are most favorable when considered per hole created: $-1.46(-1.57)$, $-1.20(-1.32)$ and $-0.97(-1.22) \mathrm{eV}$ for single, double and triple $\mathrm{Mn}^{3+}$ defect coupling, when using the B3LYP (B97-3) $\mathrm{XC}$ functional. Again, we note that negative $\Delta H_{f}$ values indicate a physically unstable $\epsilon_{f}$, as the material would spontaneously lose electrons; however, we emphasize the trend in stability of different defects. Compensating Mn vacancies were also considered, but found to be higher in energy than compensation via $\epsilon_{f}$

Our positioning of the VBM at the (100) surface is in good agreement with previous computations by Toroker et al. using hybrid-DFT methods, where a periodic slab model was used with a vacuum region and the electrostatic potential in the vacuum gap taken as the reference vacuum level. With this model, they obtained $\epsilon_{V B M}$ of $-4.48,-4.96,-5.28$, and -5.57 $\mathrm{eV}$ for the PBE+U, HSE, PBEO, and GOWO $(\mathrm{DFT}+\mathrm{U})$ methods; ${ }^{12}$ Stevanovic et al. used a similar technique to obtain $I_{v}=5.08 \mathrm{eV}$. However, neither our nor other authors' results match with the experimental estimates of $-7.5 \pm 0.8 \mathrm{eV}$, taken from photoelectron spectroscopy (PES) measurements by Fujimori et al., ${ }^{101}$ though these relate to the room temperature 
PM phase. A position of the VB can also be implied from the PES-BIS (bremsstrahlung isochromate spectroscopy) measurements of van Elp et al., where the CBM was reported as being $-3.6 \pm 1.2 \mathrm{eV}^{76}$ this again positions the VBM well below our estimates. The offset between experimental and computational results is worth remembering when interpreting our defect calculations: a lower value of $\epsilon_{V B M}$ stabilizes electrons, which will shift the equilibrium between $\epsilon_{f}$-compensated charged defects such that positively charged defects will be more favored.

4.2. Intrinsic Defects. The formation energies of neutral and positively charged oxygen surface vacancies are presented in Figure 4. $\Delta H_{f}\left(\mathrm{~V}_{\mathrm{O}}^{\mathrm{x}}\right)$ is almost identical to the bulk at 5.88

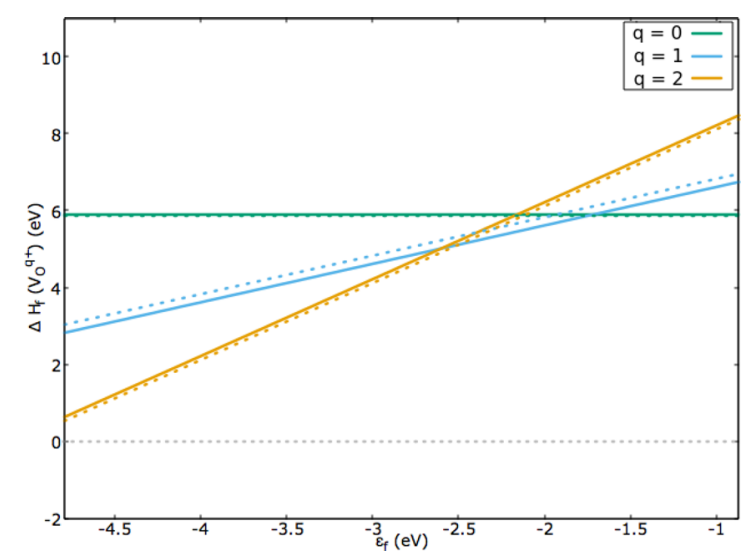

Figure 4. $\Delta H_{f}$ as a function of $\epsilon_{f}$ for $\mathrm{V}_{\mathrm{O}}{ }^{q+}$ in surface (solid) and bulk (dashed) environments, with charge $q=0$ (green), 1 (blue) and 2 (yellow). The minimum and maximum of $\epsilon_{f}$ on the $x$-axis represents the band edges for the valence and conduction band, respectively. The $0 \mathrm{eV}$ line on the $y$-axis, splitting endo- and exothermic processes, is marked by a gray dashed line.

(5.60) eV for the B3LYP (B97-3) XC functional, differing by only $0.02 \mathrm{eV}$. This difference relative to bulk increases $\sim 0.2 \mathrm{eV}$ for $\mathrm{V}_{\mathrm{O}}^{\bullet}$, with $\Delta H_{f}\left(\mathrm{~V}_{\mathrm{O}}^{\bullet}\right)=2.81(2.37) \mathrm{eV}$ at the surface when considering $\epsilon_{f}=\epsilon_{V B M} ;$ for $\mathrm{V}_{\mathrm{O}}^{\bullet \bullet}, \Delta H_{f}\left(\mathrm{~V}_{\mathrm{O}}^{\bullet \bullet}\right)$ is then almost identical for the surface and bulk, at $0.63(-0.04) \mathrm{eV}$ for the B3LYP (B97-3) XC functional. Analysis of the defect levels shows that, like the bulk, the favored spin configuration when ionizing to the $\mathrm{V}_{\mathrm{O}}^{\bullet}$ states is low-spin (LS): $I_{v}^{L S}\left(\mathrm{~V}_{\mathrm{O}}^{\mathrm{x}} \rightarrow \mathrm{V}_{\mathrm{O}}^{\bullet}\right)=$ $2.84 \mathrm{eV}$ compared to $I_{v}^{H S}\left(\mathrm{~V}_{\mathrm{O}}^{\mathrm{x}} \rightarrow \mathrm{V}_{\mathrm{O}}^{\bullet}\right)=3.13 \mathrm{eV}$ for high-spin (HS) configurations, using the B3LYP XC functional. Also similar to the bulk, the structural integrity of the void is preserved, with neighboring bond distances remaining close to the bulk values. However, removing a second electron from the oxygen vacancy is more difficult: $I_{v}\left(\mathrm{~V}_{\mathrm{O}}^{\bullet} \rightarrow \mathrm{V}_{\mathrm{O}}^{\bullet \bullet}\right)$ and $I_{a}\left(\mathrm{~V}_{\mathrm{O}}^{\bullet} \rightarrow\right.$ $\left.\mathrm{V}_{\mathrm{O}}^{\bullet \bullet}\right)$ are $4.06(4.22)$ and $2.60(2.73) \mathrm{eV}$, respectively, with the B3LYP (B97-3) XC functional, which is $\sim 0.6 \mathrm{eV}$ larger than for the bulk. The structure of the defect remains relatively unchanged.

4.3. $\mathrm{CO}_{2}$ Adsorption. Rock salt oxides have recently been proposed as candidate materials for the catalytic transformation of $\mathrm{CO}_{2}{ }^{10,11,14}$ and here we investigate the initial step of that reaction: $\mathrm{CO}_{2}$ surface adsorption. Previously, it has been shown that surface defects on $\mathrm{MgO}$, specifically oxygen vacancies, can affect $\mathrm{CO}_{2}$ adsorbate binding, ${ }^{55}$ both structurally and energetically, which is further amplified by the presence of extrinsic cation dopants like $\mathrm{Mn}_{\mathrm{Mg}}{ }^{33}$ A favorable initial step involves charge transfer from the support to the $\mathrm{CO}_{2}$, which results in bending of the linear $\mathrm{CO}_{2}$, and this can be aided by high-energy defect levels associated with oxygen vacancies.

There are two possible orientations for a $\mathrm{CO}_{2}$ molecule on the (100) surface: parallel or perpendicular to the surface $\mathrm{xy}$ plane. $^{55}$ Downing et al. showed that, for pure $\mathrm{MgO}$, parallel adsorption is stronger over the pristine surface, whereas perpendicular orientation is more favorable in the presence of $\mathrm{V}_{\mathrm{O}}$. In the case of $\mathrm{MnO}$, parallel adsorption is again stronger over the pristine surface than perpendicular, with the $\mathrm{C}$ atom interacting with a surface oxygen (Figure 5) with an adsorption
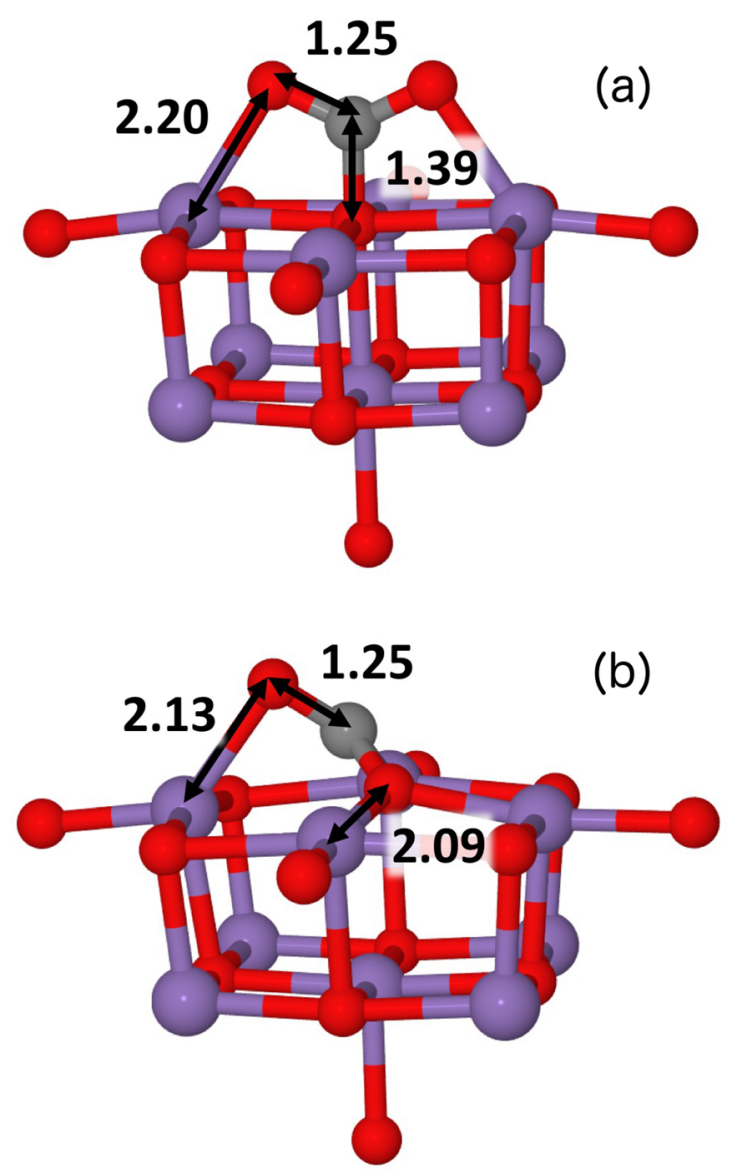

Figure 5. Structure of $\mathrm{CO}_{2}$ adsorbed over: (a) a perfect (100) $\mathrm{MnO}$ surface and (b) a $\mathrm{V}_{\mathrm{O}}^{\mathrm{x}}$ defect at the structure surface. In the latter case, the $\mathrm{CO}_{2}$ is seen to fill the oxygen vacancy. Red, purple, and gray spheres represent $\mathrm{O}, \mathrm{Mn}$, and $\mathrm{C}$ atoms.

energy of $-0.64 \mathrm{eV}$ (Table 3 ). This result is very similar to previous work on $\mathrm{MgO}(-0.68 \mathrm{eV})$ and $\mathrm{Mn}$-doped $\mathrm{MgO}$ $(-0.66$ to $-0.79 \mathrm{eV}) .^{33,55}$ For $\mathrm{V}_{\mathrm{O}}^{\mathrm{x}}$, the energetics of $\mathrm{CO}_{2}$ adsorption in parallel or perpendicular configurations are similar $(2.60 \mathrm{eV})$, with structural analysis showing that, in both cases, the $\mathrm{CO}_{2}$ adopts a bent structure coordinated with both the defect and the surface atoms (Figure 5). In particular, one oxygen from the $\mathrm{CO}_{2}$ fills the void while the second oxygen coordinates with a surface $\mathrm{Mn}$, resulting in $\angle(\mathrm{OCO})$ of $115.5^{\circ}$. This angular distortion prevents the adsorption energy from being as strong as for $\mathrm{CO}_{2} \mathrm{z}$-aligned over $\mathrm{MgO}$. $^{55}$

As we remove an electron from $\mathrm{V}_{\mathrm{O}}^{\mathrm{x}}$ to form $\mathrm{V}_{\mathrm{O}}^{\bullet}$, the interaction between $\mathrm{CO}_{2}$ and $\mathrm{MnO}$ weakens yet the adsorbate is still strongly coordinated with the surface, and the internal angle of $\angle(\mathrm{OCO})$ is $119.7^{\circ}$. The maintenance of an adsorbed structure, yet weakening of the adsorption energy, shows how 
Table 3. $\mathrm{CO}_{2}$ Adsorption Energies on the $\mathrm{MnO}$ (100) surface, both Pristine and with Oxygen Vacancies, As Aligned along either the $x$ - or $z$-Axis and Calculated with the B3LYP XC Functional ${ }^{a}$

\begin{tabular}{|c|c|c|c|}
\hline & & $x$-aligned & $z$-aligned \\
\hline \multirow[t]{3}{*}{$\mathrm{O}_{\mathrm{O}}^{\mathrm{x}}$} & $\mathrm{MnO}$ & -0.64 & - \\
\hline & $\mathrm{Mn}-\mathrm{MgO}^{33}$ & -0.65 & 0.00 \\
\hline & $\mathrm{MgO}^{55}$ & -0.68 & 0.11 \\
\hline \multirow[t]{4}{*}{$\mathrm{V}_{\mathrm{O}}^{\mathrm{x}}$} & $\mathrm{MnO}$ & -2.61 & -2.61 \\
\hline & $\mathrm{Mn}-\mathrm{MgO}^{33}$ & -2.00 & -3.13 \\
\hline & $\mathrm{MgO}^{55}$ & -2.36 & -3.52 \\
\hline & $\mathrm{MgO}^{102}$ & -1.85 & -3.23 \\
\hline \multirow[t]{4}{*}{$\mathrm{V}_{\mathrm{O}}^{\bullet}$} & $\mathrm{MnO}$ & -1.60 & - \\
\hline & $\mathrm{Mn}-\mathrm{MgO}^{33}$ & -2.00 & -1.12 \\
\hline & $\mathrm{MgO}^{55}$ & -0.71 & -1.11 \\
\hline & $\mathrm{MgO}^{102}$ & -0.23 & -1.04 \\
\hline \multirow[t]{3}{*}{$\mathrm{V}_{\mathrm{O}}^{\bullet \bullet}$} & $\mathrm{MnO}$ & -0.02 & -0.07 \\
\hline & $\mathrm{Mn}-\mathrm{MgO}^{33}$ & 0.90 & -0.09 \\
\hline & $\mathrm{MgO}^{55}$ & 0.11 & 0.04 \\
\hline
\end{tabular}

${ }^{a}$ Also presented are previously calculated results for $\mathrm{CO}_{2}$ adsorption on $\mathrm{MgO}$ and $\mathrm{Mn}_{\text {surf }}-\mathrm{MgO}$ using the B3LYP XC functional and similar basis sets. ${ }^{33,55}$ All values are given in $\mathrm{eV}$.

important it is for electron transfer to occur from the support to the adsorbate. This factor is further exemplified for $\mathrm{V}_{\mathrm{O}}^{\bullet \bullet}$, where the $\mathrm{CO}_{2}$ only interacts weakly with the support, at a separation distance of $3.5 \AA$. Thus, we can conclude that defect electrons positioned high in the band gap, as made available through the existence of oxygen vacancies, are important for catalytic $\mathrm{CO}_{2}$ activation, in contrast with, e.g., $\mathrm{MgO}{ }^{55}$ Furthermore, one can consider these observations are also indicative of preferential conditions for the reverse reaction of $\mathrm{CO}$ oxidation over $\mathrm{MnO}$, where weaker $\mathrm{CO}_{2}$ binding is preferential for the product to leave the support surface; ${ }^{103}$ in this case, formation of $\mathrm{V}_{\mathrm{O}}^{\bullet \bullet}$ would be most beneficial.

\section{SUMMARY AND CONCLUSIONS}

We have used embedded cluster QM/MM calculations to investigate the electronic and energetic stability of $\mathrm{MnO}$ in pristine and defective bulk and in similar arrangements for (100) surfaces. We have modeled the system using low-energy principal diagonal antiferromagnetic ordering and the appropriate rhombohedrally distorted unit cell throughout.

For the bulk system, our calculations have shown that the valence band maximum and conduction band minimum are positioned at $-4.79 \mathrm{eV}$ and $-0.87 \mathrm{eV}$ relative to the vacuum level, with the valence band maximum formed of $\mathrm{Mn} 3 \mathrm{~d}$-states. We then use our model to calculate the preferential defect formation to be ionized vacancies, with a $2+$ charge, when atomic defects are introduced with electron removal to the Fermi Level, $\epsilon_{f}$, at the valence band maximum; at the conduction band minimum, double-charged $\mathrm{Mn}$ vacancies are far more stable than other defects, being exothermic to form in most cases. Schottky defects, whereby charged defects compensate each other to maintain charge neutrality at the macroscopic level, are most preferable for a combination of $V_{O}^{\bullet \bullet}$ and $V_{M n}^{\prime \prime}$ defects: the formation energy is $2.40 \mathrm{eV}$ when using the B3LYP XC functional. The defect levels for the charged vacancies were also investigated, with the $\mathrm{V}_{\mathrm{O}}^{\mathrm{x}}$ and $\mathrm{V}_{\mathrm{O}}^{\bullet}$ defects positioned mid band gap, similar to $\mathrm{MgO}$; the $\mathrm{V}_{\mathrm{Mn}}^{\prime}$ and $\mathrm{V}_{\mathrm{Mn}}^{\prime \prime}$ defects are marginally lower in energy.

For the (100) surface, the structure proves similar to previous calculations, with interlayer contraction and slight oxygen protrusion from the surface. Again, we pursued calculations for the formation of oxygen vacancies, with results almost identical to the bulk, which highlights the relative stability of the surface; most defect levels were also similar to those in the bulk, with a notable exception being the $\mathrm{V}_{\mathrm{O}}^{\bullet}$ state, which was $\sim 0.6 \mathrm{eV}$ lower for the surface. Finally, we presented testing of the chemical properties of the pristine and defective (100) surface for applications in $\mathrm{CO}_{2}$ transformation. We show that the presence of defect-levels at surface vacancies on an $\mathrm{MnO}$ catalyst are crucial for activating the $\mathrm{CO}_{2}$, with charge transfer resulting in strong adsorption and structural distortion. We are currently expanding this investigation to include $\mathrm{MnO}_{x}$ materials, where the higher oxidation state of the cation may influence the electronic and energetic properties.

\section{ASSOCIATED CONTENT}

\section{S Supporting Information}

The Supporting Information is available free of charge on the ACS Publications website at DOI: 10.1021/acs.jpcc.8b07846.

Edited basis set for an $\mathrm{Mn}$ atom, as used in our calculations, documentation of periodic calculations for the formation enthalpies of $\mathrm{MnO}$, figures illustrating defect formation enthalpies, and a pictorial representation of the defect levels for neutral and charged defects in $\mathrm{MnO}$ when using the B97-3 exchange-correlation functional (PDF)

\section{AUTHOR INFORMATION}

\section{Corresponding Author}

*(A.J.L.) E-mail: LogsdailA@cardiff.ac.uk. ORCID $\odot$

Andrew J. Logsdail: 0000-0002-2277-415X

Thomas W. Keal: 0000-0001-8747-3975

Alexey A. Sokol: 0000-0003-0178-1147

Notes

The authors declare no competing financial interest.

The raw data from which all energetic results were derived is available to access at DOI: 10.17035/d.2018.0052063074.

\section{ACKNOWLEDGMENTS}

The authors are grateful to David Scanlon and John Buckeridge for discussions associated with this work. A.J.L. acknowledges the Ramsay Memorial Trust and University College London for the provision of a Ramsay Fellowship. C.A.D. acknowledges the Molecular Modelling and Materials Science Industrial Doctorate Centre (M3S IDC) and the Science and Technology Facilities Council (STFC) for funding. A.J.L., T.W.K., P.S., A.A.S. and C.R.A.C. acknowledge funding from EPSRC Grants EP/IO30662/1 and EP/ K038419/1. The authors acknowledge the use of computing facilities provided by ARCCA at Cardiff University, HPC Wales, and the ARCHER high-performance computing facilities via our membership of the UK HPC Materials Chemistry Consortium (EP/L000202). Finally, the authors wish to thank Joachim Sauer and Hajo Freund for many stimulating discussions on solid state and surface chemistry. 


\section{REFERENCES}

(1) Al-Abadleh, H. A.; Grassian, V. H. Oxide Surfaces As Environmental Interfaces. Surf. Sci. Rep. 2003, 52, 63-161.

(2) Woodruff, D. P. Quantitative Structural Studies of Corundum and Rocksalt Oxide Surfaces. Chem. Rev. 2013, 113, 3863-3886.

(3) Noguera, C. Physics and Chemistry at Oxide Surfaces; Cambridge University Press: 1996.

(4) Pacchioni, G. Oxygen Vacancy: The Invisible Agent on Oxide Surfaces. ChemPhysChem 2003, 4, 1041-1047.

(5) Haider, M. H.; Dummer, N. F.; Knight, D. W.; Jenkins, R. L.; Howard, M.; Moulijn, J.; Taylor, S. H.; Hutchings, G. J. Efficient Green Methanol Synthesis from Glycerol. Nat. Chem. 2015, 7, 10281032.

(6) McFarland, E. W.; Metiu, H. Catalysis by Doped Oxides. Chem. Rev. 2013, 113, 4391-4427.

(7) Cui, Y.; Shao, X.; Baldofski, M.; Sauer, J.; Nilius, N.; Freund, H.J. Adsorption, Activation, and Dissociation of Oxygen on Doped Oxides. Angew. Chem., Int. Ed. 2013, 52, 11385-11387.

(8) Stavale, F.; Shao, X.; Nilius, N.; Freund, H.-J.; Prada, S.; Giordano, L.; Pacchioni, G. Donor Characteristics of TransitionMetal-Doped Oxides: Cr-Doped MgO Versus Mo-Doped CaO. J. Am. Chem. Soc. 2012, 134, 11380-11383.

(9) Ganduglia-Pirovano, M. V.; Hofmann, A.; Sauer, J. Oxygen Vacancies in Transition Metal and Rare Earth Oxides: Current State of Understanding and Remaining Challenges. Surf. Sci. Rep. 2007, 62, 219-270.

(10) Wang, S.; Yan, S.; Ma, X.; Gong, J. Recent Advances in Capture of Carbon Dioxide Using Alkali-Metal-Based Oxides. Energy Environ. Sci. 2011, 4, 3805-3819.

(11) Choi, S.; Drese, J. H.; Jones, C. W. Adsorbent Materials for Carbon Dioxide Capture from Large Anthropogenic Point Sources. ChemSusChem 2009, 2, 796-854.

(12) Toroker, M. C.; Kanan, D. K.; Alidoust, N.; Isseroff, L. Y.; Liao, P.; Carter, E. A. First Principles Scheme to Evaluate Band Edge Positions in Potential Transition Metal Oxide Photocatalysts and Photoelectrodes. Phys. Chem. Chem. Phys. 2011, 13, 16644-16654.

(13) Stevanović, V.; Lany, S.; Ginley, D. S.; Tumas, W.; Zunger, A. Assessing Capability of Semiconductors to Split Water Using Ionization Potentials and Electron Affinities Only. Phys. Chem. Chem. Phys. 2014, 16, 3706-3714.

(14) Hammami, R.; Dhouib, A.; Fernandez, S.; Minot, C. CO2 Adsorption on (001) Surfaces of Metal Monoxides with Rock-Salt Structure. Catal. Today 2008, 139, 227-233.

(15) van den Berg, F.; Glezer, J.; Sachtler, W. the Role of Promoters in $\mathrm{COH} 2$ Reactions: Effects of $\mathrm{MnO}$ and $\mathrm{MoO} 2$ in Silica-Supported Rhodium Catalysts. J. Catal. 1985, 93, 340-352.

(16) De Jong, K.; Glezer, J.; Kuipers, H.; Knoester, A.; Emeis, C. Highly Dispersed $\mathrm{Rh} / \mathrm{SiO} 2$ and $\mathrm{Rh} / \mathrm{MnO} / \mathrm{SiO} 2$ Catalysts: 1 . Synthesis, Characterization, and CO Hydrogenation Activity. J. Catal. 1990, 124, 520-529.

(17) Xu, L.; Wang, Q.; Xu, Y.; Huang, J. A New Supported Fe-MnO Catalyst for the Production of Light Olefins from Syngas. I. Effect of Support on the Catalytic Performance. Catal. Lett. 1994, 24, 177185.

(18) Seok, S.-H.; Han, S. H.; Lee, J. S. the Role of $\mathrm{MnO}$ in Ni/MnOAl2O3 Catalysts for Carbon Dioxide Reforming of Methane. Appl. Catal., A 2001, 215, 31-38.

(19) Tanaka, Y.; Utaka, T.; Kikuchi, R.; Takeguchi, T.; Sasaki, K.; Eguchi, K. Water Gas Shift Reaction for the Reformed Fuels over $\mathrm{Cu} /$ MnO Catalysts Prepared Via Spinel-Type Oxide. J. Catal. 2003, 215, 271-278.

(20) Liu, Y.; Zhao, X.; Li, F.; Xia, D. Facile Synthesis of MnO/C Anode Materials for Lithium-Ion Batteries. Electrochim. Acta 2011, 56, 6448-6452.

(21) Lei, S.; Tang, K.; Fang, Z.; Liu, Q.; Zheng, H. Preparation of $\alpha$ $\mathrm{Mn} 2 \mathrm{O} 3$ and $\mathrm{MnO}$ from Thermal Decomposition of $\mathrm{MnCO} 3$ and Control of Morphology. Mater. Lett. 2006, 60, 53-56.
(22) Kanan, D. K.; Carter, E. A. Band Gap Engineering of MnO Via ZnO Alloying: A Potential New Visible-Light Photocatalyst. J. Phys. Chem. C 2012, 116, 9876-9887.

(23) Kanan, D. K.; Carter, E. A. Optical Excitations in $\mathrm{MnO}$ and $\mathrm{MnO}: \mathrm{ZnO}$ Via Embedded CASPT2 Theory and Their Implications for Solar Energy Conversion. J. Phys. Chem. C 2013, 117, 1381613826 .

(24) Kanan, D. K.; Keith, J. A.; Carter, E. A. Water Adsorption on $\mathrm{MnO}: \mathrm{ZnO}(001)$ from Single Molecules to Bilayer Coverage. Surf. Sci. 2013, 617, 218-224.

(25) Kanan, D. K.; Carter, E. A.; Dupuis, M.; Stoll, H.; Preuss, H.; Dam, H. J. J. V.; Wang, D.; Nieplocha, J.; Apra, E.; Windus, T. L.; et al. Ab Initio Study of Electron and Hole Transport in Pure and Doped $\mathrm{MnO}$ and $\mathrm{MnO}: \mathrm{ZnO}$ Alloy. J. Mater. Chem. A 2013, 1, 92469256.

(26) Kanan, D. K.; Keith, J. A.; Carter, E. A. First-Principles Modeling of Electrochemical Water Oxidation on $\mathrm{MnO}: \mathrm{ZnO}(001)$. ChemElectroChem 2014, 1, 407-415.

(27) Peng, H.; Ndione, P. F.; Ginley, D. S.; Zakutayev, A.; Lany, S. Design of Semiconducting Tetrahedral Mn 1 X Zn X O Alloys and Their Application to Solar Water Splitting. Phys. Rev. X 2015, 5, 021016.

(28) Honkala, K. Tailoring Oxide Properties: An Impact on Adsorption Characteristics of Molecules and Metals. Surf. Sci. Rep. 2014, 69, 366-388.

(29) Hattori, H. Solid Base Catalysts: Generation of Basic Sites and Application to Organic Synthesis. Appl. Catal., A 2001, 222, 247-259.

(30) Goniakowski, J.; Noguera, C. Atomic and Electronic Structure of Steps and Kinks on $\mathrm{MgO}(100)$ and $\mathrm{MgO}(110)$. Surf. Sci. 1995, 340, 191-204.

(31) Pacchioni, G.; Freund, H. Electron Transfer at Oxide Surfaces. the $\mathrm{MgO}$ Paradigm: From Defects to Ultrathin Films. Chem. Rev. 2013, 113, 4035-4072.

(32) Nilius, N.; Freund, H.-J. Activating Nonreducible Oxides Via Doping. Acc. Chem. Res. 2015, 48, 1532-1539.

(33) Logsdail, A. J.; Downing, C. A.; Keal, T. W.; Sherwood, P.; Sokol, A. A.; Catlow, C. R. A. Modelling the Chemistry of Mn-Doped $\mathrm{MgO}$ for Bulk and (100) Surfaces. Phys. Chem. Chem. Phys. 2016, 18, 28648-28660.

(34) Johnston, W. D.; Heikes, R. R. A Study of the LixMn(1-X)O System. J. Am. Chem. Soc. 1956, 78, 3255-3260.

(35) O'Keeffe, M.; Valigi, M. the Electrical Properties and Defect Structure of Pure and Chromium-Doped MnO. J. Phys. Chem. Solids 1970, 31, 947-962.

(36) Pearson, W. B. A Handbook of Lattice Spacings and Structures of Metals and Alloys: International Series of Monographs on Metal Physics and Physical Metallurgy, 4th ed.; Elsevier: 2013.

(37) Kittel, C. Introduction to Solid State Physics, 8th ed.; Wiley: New York, 2004.

(38) Harrison, W. A. Heisenberg Exchange in the Magnetic Monoxides. Phys. Rev. B: Condens. Matter Mater. Phys. 2007, 76, 054417.

(39) Corà, F.; Alfredsson, M.; Mallia, G.; Middlemiss, D. S.; Mackrodt, W. C.; Dovesi, R.; Orlando, R. The Performance of Hybrid Density Functionals in Solid State Chemistry. Struct. Bonding 2004, 113, 171-232.

(40) Feng, X. Electronic Structure of $\mathrm{MnO}$ and $\mathrm{CoO}$ from the B3LYP Hybrid Density Functional Method. Phys. Rev. B: Condens. Matter Mater. Phys. 2004, 69, 155107.

(41) Franchini, C.; Bayer, V.; Podloucky, R.; Paier, J.; Kresse, G. Density Functional Theory Study of $\mathrm{MnO}$ by a Hybrid Functional Approach. Phys. Rev. B: Condens. Matter Mater. Phys. 2005, 72, 045132 .

(42) Franchini, C.; Podloucky, R.; Paier, J.; Marsman, M.; Kresse, G. Ground-State Properties of Multivalent Manganese Oxides: Density Functional and Hybrid Density Functional Calculations. Phys. Rev. B: Condens. Matter Mater. Phys. 2007, 75, 195128.

(43) Schrön, A.; Rödl, C.; Bechstedt, F. Energetic Stability and Magnetic Properties of $\mathrm{MnO}$ in the Rocksalt, Wurtzite, and Zinc- 
Blende Structures: Influence of Exchange and Correlation. Phys. Rev. B: Condens. Matter Mater. Phys. 2010, 82, 165109.

(44) Logsdail, A. J.; Downing, C. A.; Catlow, C. R. A.; Sokol, A. A. Magnetic Coupling Constants for MnO As Calculated Using Hybrid Density Functional Theory. Chem. Phys. Lett. 2017, 690, 47-53.

(45) Morosin, B. Exchange Striction Effects in $\mathrm{MnO}$ and MnS. Phys. Rev. B 1970, 1, 236-243.

(46) Cheetham, A. K.; Hope, D. A. O. Magnetic Ordering and Exchange Effects in the Antiferromagnetic Solid Solutions MnXNi(1X)O. Phys. Rev. B: Condens. Matter Mater. Phys. 1983, 27, 69646967.

(47) Shaked, H.; Faber, J.; Hitterman, R. L. Low-Temperature Magnetic Structure of Mno: A High-Resolution Neutron-Diffraction Study. Phys. Rev. B: Condens. Matter Mater. Phys. 1988, 38, 1190111903.

(48) Sherwood, P.; De Vries, A. H.; Guest, M. F.; Schreckenbach, G.; Catlow, C. R. A.; French, S. A.; Sokol, A. A.; Bromley, S. T.; Thiel, W.; Turner, A. J.; et al. QUASI: A General Purpose Implementation of the QM/MM Approach and Its Application to Problems in Catalysis. J. Mol. Struct.: THEOCHEM 2003, 632, 1-28.

(49) Metz, S.; Kästner, J.; Sokol, A. A.; Keal, T. W.; Sherwood, P. ChemShell-a Modular Software Package for QM/MM Simulations. Wiley Interdiscip. Rev.: Comput. Mol. Sci. 2014, 4, 101-110.

(50) Valiev, M.; Bylaska, E. J.; Govind, N.; Kowalski, K.; Straatsma, T. P.; Van Dam, H. J. J. V.; Wang, D.; Nieplocha, J.; Apra, E.; Windus, T. L.; et al. NWChem: A Comprehensive and Scalable Open-Source Solution for Large Scale Molecular Simulations. Comput. Phys. Commun. 2010, 181, 1477-1489.

(51) Gale, J. D. GULP: A Computer Program for the SymmetryAdapted Simulation of Solids. J. Chem. Soc., Faraday Trans. 1997, 93, 629-637.

(52) Gale, J. D.; Rohl, A. L. the General Utility Lattice Program (GULP). Mol. Simul. 2003, 29, 291-341.

(53) Gale, J. D. GULP: Capabilities and Prospects. Z. Kristallogr. Cryst. Mater. 2005, 220, 552-554.

(54) Kästner, J.; Carr, J. M.; Keal, T. W.; Thiel, W.; Wander, A.; Sherwood, P. DL-FIND: An Open-Source Geometry Optimizer for Atomistic Simulations. J. Phys. Chem. A 2009, 113, 11856-11865.

(55) Downing, C. A.; Sokol, A. A.; Catlow, C. R. A. the Reactivity of $\mathrm{CO} 2$ on the MgO (100) Surface. Phys. Chem. Chem. Phys. 2014, 16, 184-195.

(56) Downing, C. A.; Sokol, A. A.; Catlow, C. R. A. the Reactivity of $\mathrm{CO} 2$ and $\mathrm{H} 2$ at Trapped Electron Sites at an Oxide Surface. Phys. Chem. Chem. Phys. 2014, 16, 21153-21156.

(57) Scanlon, D. O.; Dunnill, C. W.; Buckeridge, J.; Shevlin, S. A.; Logsdail, A. J.; Woodley, S. M.; Catlow, C. R. A.; Powell, M. J.; Palgrave, R. G.; Parkin, I. P.; et al. Band Alignment of Rutile and Anatase TiO2. Nat. Mater. 2013, 12, 798-801.

(58) Berger, D.; Logsdail, A. J.; Oberhofer, H.; Farrow, M. R.; Catlow, C. R. A.; Sherwood, P.; Sokol, A. A.; Blum, V.; Reuter, K. Embedded-Cluster Calculations in a Numeric Atomic Orbital Density-Functional Theory Framework. J. Chem. Phys. 2014, 141, 024105.

(59) Buckeridge, J.; Butler, K. T.; Catlow, C. R. A.; Logsdail, A. J.; Scanlon, D. O.; Shevlin, S. A.; Woodley, S. M.; Sokol, A. A.; Walsh, A. Polymorph Engineering of $\mathrm{TiO}_{2}$ : Demonstrating How Absolute Reference Potentials Are Determined by Local Coordination. Chem. Mater. 2015, 27, 3844-3851.

(60) Buckeridge, J.; Catlow, C. R. A.; Farrow, M. R.; Logsdail, A. J.; Scanlon, D. O.; Keal, T. W.; Sherwood, P.; Woodley, S. M.; Sokol, A. A.; Walsh, A. Deep Vs Shallow Nature of Oxygen Vacancies and Consequent N-Type Carrier Concentrations in Transparent Conducting Oxides. Phys. Rev. Mater. 2018, 2, 54604.

(61) Piccini, G.; Alessio, M.; Sauer, J. AbInitio Calculation of Rate Constants for Molecule-Surface Reactions with Chemical Accuracy. Angew. Chem., Int. Ed. 2016, 55, 5235-5237.

(62) Komsa, H.-P.; Pasquarello, A. Finite-Size Supercell Correction for Charged Defects at Surfaces and Interfaces. Phys. Rev. Lett. 2013, 110,95505 .
(63) Freysoldt, C.; Neugebauer, J. First-Principles Calculations for Charged Defects at Surfaces, Interfaces, and Two-Dimensional Materials in the Presence of Electric Fields. Phys. Rev. B: Condens. Matter Mater. Phys. 2018, 97, 205425.

(64) Lewis, G. V.; Catlow, C. R. A. Potential Models for Ionic Oxides. J. Phys. C: Solid State Phys. 1985, 18, 1149-1161.

(65) Becke, A. D. Density-Functional Thermochemistry. III. the Role of Exact Exchange. J. Chem. Phys. 1993, 98, 5648-5652.

(66) Lee, C.; Yang, W.; Parr, R. G. Development of the ColleSalvetti Correlation-Energy Formula into a Functional of the Electron Density. Phys. Rev. B: Condens. Matter Mater. Phys. 1988, 37, 785789.

(67) Stephens, P. J.; Devlin, F. J.; Chabalowski, C. F.; Frisch, M. J. $\mathrm{Ab}$ Initio Calculation of Vibrational Absorption and Circular Dichroism Spectra Using Density Functional Force Fields. J. Phys. Chem. 1994, 98, 11623-11627.

(68) Keal, T. W.; Tozer, D. J. Semiempirical Hybrid Functional with Improved Performance in an Extensive Chemical Assessment. J. Chem. Phys. 2005, 123, 121103.

(69) Weigend, F.; Ahlrichs, R. Balanced Basis Sets of Split Valence, Triple Zeta Valence and Quadruple Zeta Valence Quality for $\mathrm{H}$ to Rn: Design and Assessment of Accuracy. Phys. Chem. Chem. Phys. 2005, 7, 3297-3305.

(70) Dolg, M.; Wedig, U.; Stoll, H.; Preuss, H. Energy-Adjusted Ab Initio Pseudopotentials for the 1st-Row Transition-Elements. J. Chem. Phys. 1987, 86, 866-872.

(71) Fender, B. E. F.; Jacobson, A. J.; Wedgwood, F. A. Covalency Parameters in $\mathrm{MnO}, \alpha \mathrm{MnS}$, and NiO. J. Chem. Phys. 1968, 48, 990994.

(72) Jost, W. Diffusion and Electrolytic Conduction in Crystals (Ionic Semiconductors). J. Chem. Phys. 1933, 1, 466-475.

(73) Sokol, A. A.; Bromley, S. T.; French, S. A.; Catlow, C. R. A.; Sherwood, P. Hybrid QM/MM Embedding Approach for the Treatment of Localized Surface States in Ionic Materials. Int. J. Quantum Chem. 2004, 99, 695-712.

(74) Xu, Y.; Schoonen, M. A. the Absolute Energy Positions of Conduction and Valence Bands of Selected Semiconducting Minerals. Am. Mineral. 2000, 85, 543-556.

(75) Sugar, J.; Corliss, C. Atomic Energy Levels of the Iron-Period Elements, Potassium Through Nickel. J. Phys. Chem. Ref. Data, Suppl. 1985, 14, 664.

(76) van Elp, J.; Potze, R. H.; Eskes, H.; Berger, R.; Sawatzky, G. A. Electronic Structure of MnO. Phys. Rev. B: Condens. Matter Mater. Phys. 1991, 44, 1530-1537.

(77) Fromme, B.; Brunokowski, U.; Kisker, E. d D Excitations and Interband Transitions in MnO: A Spin-Polarized Electron-EnergyLoss Study. Phys. Rev. B: Condens. Matter Mater. Phys. 1998, 58, 9783-9792.

(78) Kurmaev, E. Z.; Wilks, R. G.; Moewes, A.; Finkelstein, L. D.; Shamin, S. N.; Kuneš, J. Oxygen X-Ray Emission and Absorption Spectra As a Probe of the Electronic Structure of Strongly Correlated Oxides. Phys. Rev. B: Condens. Matter Mater. Phys. 2008, 77, 165127.

(79) Massidda, S.; Continenza, A.; Posternak, M.; Baldereschi, A. Band-Structure Picture for $\mathrm{MnO}$ Reexplored: A Model GW Calculation. Phys. Rev. Lett. 1995, 74, 2323-2326.

(80) Faleev, S. V.; van Schilfgaarde, M.; Kotani, T. All-Electron SelfConsistent G W Approximation: Application to $\mathrm{Si}, \mathrm{MnO}$, and $\mathrm{NiO}$. Phys. Rev. Lett. 2004, 93, 126406.

(81) Walsh, A.; Buckeridge, J.; Catlow, C. R. A.; Jackson, A. J.; Keal, T. W.; Miskufova, M.; Sherwood, P.; Shevlin, S. A.; Watkins, M. B.; Woodley, S. M.; et al. Limits to Doping of Wide Band Gap Semiconductors. Chem. Mater. 2013, 25, 2924-2926.

(82) Janthon, P.; Luo, S. A.; Kozlov, S. M.; Viñes, F.; Limtrakul, J.; Truhlar, D. G.; Illas, F. Bulk Properties of Transition Metals: A Challenge for the Design of Universal Density Functionals. J. Chem. Theory Comput. 2014, 10, 3832-3839.

(83) Lide, D. R. CRC Handbook of Chemistry and Physics, 84th ed.; CRC Press: Boca Raton, FL, 2003. 
(84) Smyth, D. M. the Defect Chemistry of Metal Oxides; Oxford University Press: Oxford, U.K., 2000.

(85) Aschauer, U.; Vonrüti, N.; Spaldin, N. A. Effect of Epitaxial Strain on Cation and Anion Vacancy Formation in MnO. Phys. Rev. B: Condens. Matter Mater. Phys. 2015, 92, 054103.

(86) Stokłosa, A. Point Defects Diagrams for Pure and Doped Manganese Oxide $\mathrm{Mn} 1 \delta \mathrm{O}$ in the Temperature Range of 11731830K. Mater. Chem. Phys. 2012, 134, 1136-1145.

(87) Ohama, N.; Hamaguchi, Y. Determination of the Exchange Integrals in $\beta-\mathrm{MnO}_{2}$. J. Phys. Soc. Jpn. 1971, 30, 1311-1318.

(88) Hed, A. Z.; Tannhauser, D. S. High-Temperature Electrical Properties of Manganese Monoxide. J. Chem. Phys. 1967, 47, 20902103.

(89) Keller, M.; Dieckmann, R. Defect Structure and Transport Properties of Manganese Oxides: (I) the Nonstoichiometry of Manganosite (Mn1- $\Delta \mathrm{O})$. Ber. Bunsenges. Phys. Chem. 1985, 89, 883-893.

(90) Gvishi, M.; Tallan, N.; Tannhauser, D. the Hall Mobility of Electrons and Holes in $\mathrm{MnO}$ at High Temperature. Solid State Commun. 1968, 6, 135-137.

(91) De Wit, H.; Crevecoeur, C. n-Type Hall Effect in MnO. Phys. Lett. A 1967, 25, 393-394.

(92) Pai, M.; Honig, J. Electrical and Thermoelectric Properties of Undoped MnO Single Crystals. J. Solid State Chem. 1981, 40, 59-63.

(93) Martins, R. M. Electronic Structure: Basic Theory and Practical Methods; Cambridge University Press: 2004.

(94) Gibson, A.; Haydock, R.; LaFemina, J. P. Stability of Vacancy Defects in MgO: The Role of Charge Neutrality. Phys. Rev. B: Condens. Matter Mater. Phys. 1994, 50, 2582-2592.

(95) Sokol, A. A.; French, S. A.; Bromley, S. T.; Catlow, C. R. A.; van Dam, H. J. J.; Sherwood, P. Point Defects in ZnO. Faraday Discuss. 2007, 134, 267-282.

(96) Logsdail, A. J.; Mora-Fonz, D.; Scanlon, D. O.; Catlow, C. R. A.; Sokol, A. A. Structural, Energetic and Electronic Properties of (100) Surfaces for Alkaline Earth Metal Oxides As Calculated with Hybrid Density Functional Theory. Surf. Sci. 2015, 642, 58-65.

(97) Okazawa, T.; Kido, Y. Surface Structure and Lattice Vibrations of $\mathrm{MnO}(001)$ Analyzed by High-Resolution Medium Energy Ion Scattering Spectroscopy. Surf. Sci. 2004, 556, 101-108.

(98) Soares, E. A.; Paniago, R.; de Carvalho, V. E.; Lopes, E. L.; Abreu, G. J. P.; Pfannes, H.-D. Quantitative Low-Energy Electron Diffraction Analysis of MnO (100) Films Grown on Ag (100). Phys. Rev. B: Condens. Matter Mater. Phys. 2006, 73, 035419.

(99) Momida, H.; Oguchi, T. First-Principles Studies of Antiferromagnetic $\mathrm{MnO}$ and $\mathrm{NiO}$ Surfaces. J. Phys. Soc. Jpn. 2003, 72, 588-593.

(100) Bayer, V.; Franchini, C.; Podloucky, R. Ab Initio Study of the Structural, Electronic, and Magnetic Properties of MnO (100) and MnO (110). Phys. Rev. B: Condens. Matter Mater. Phys. 2007, 75, 035404.

(101) Fujimori, A.; Kimizuka, N.; Akahane, T.; Chiba, T.; Kimura, S.; Minami, F.; Siratori, K.; Taniguchi, M.; Ogawa, S.; Suga, S. Electronic Structure of MnO. Phys. Rev. B: Condens. Matter Mater. Phys. 1990, 42, 7580-7586.

(102) Florez, E.; Fuentealba, P.; Mondragon, F. Chemical Reactivity of Oxygen Vacancies on the MgO Surface: Reactions with $\mathrm{CO} 2, \mathrm{NO} 2$ and Metals. Catal. Today 2008, 133-135, 216-222.

(103) Ramesh, K.; Chen, L.; Chen, F.; Liu, Y.; Wang, Z.; Han, Y.-F. Re-Investigating the $\mathrm{CO}$ Oxidation Mechanism over Unsupported $\mathrm{MnO}, \mathrm{Mn} 2 \mathrm{O} 3$ and $\mathrm{MnO} 2$ Catalysts. Catal. Today 2008, 131, 477482. 